\title{
Prediction of phycoremediation of As(III) and $A s(V)$ from synthetic wastewater by Chlorella pyrenoidosa using artificial neural network
}

\author{
M. S. Podder ${ }^{1}$ C. B. Majumder ${ }^{1}$
}

Received: 15 March 2016/ Accepted: 21 February 2017/Published online: 4 March 2017

(C) The Author(s) 2017. This article is published with open access at Springerlink.com

\begin{abstract}
An artificial neural network (ANN) model was developed to predict the phycoremediation efficiency of Chlorella pyrenoidosa for the removal of both As(III) and $\mathrm{As}(\mathrm{V})$ from synthetic wastewater based on 49 data-sets obtained from experimental study and increased the data using CSCF technique. The data were divided into training $(60 \%)$ validation $(20 \%)$ and testing $(20 \%)$ sets. The data collected was used for training a three-layer feed-forward back propagation (BP) learning algorithm having 4-5-1 architecture. The model used tangent sigmoid transfer function at input to hidden layer (tansing) while a linear transfer function (purelin) was used at output layer. Comparison between experimental results and model results gave a high correlation coefficient $\left(\mathrm{R}_{\text {allANN }}^{2}\right.$ equal to 0.99987 for both ions and exhibited that the model was able to predict the phycoremediation of $\mathrm{As}(\mathrm{III})$ and $\mathrm{As}(\mathrm{V})$ from wastewater. Experimental parameters influencing phycoremediation process like $\mathrm{pH}$, inoculum size, contact time and initial arsenic concentration [either As(III) or $\mathrm{As}(\mathrm{V})]$ were investigated. A contact time of $168 \mathrm{~h}$ was mainly required for achieving equilibrium at $\mathrm{pH} 9.0$ with an inoculum size of $10 \%(\mathrm{v} / \mathrm{v})$. At optimum conditions, metal ion uptake enhanced with increasing initial metal ion concentration.
\end{abstract}

Electronic supplementary material The online version of this article (doi:10.1007/s13201-017-0547-z) contains supplementary material, which is available to authorized users.

M. S. Podder

mou.chem11@gmail.com

1 Department of Chemical Engineering, Indian Institute of Technology, Roorkee 247667, India
Keywords Arsenic - Wastewater - Phycoremediation · Chlorella pyrenoidosa $\cdot$ Artificial neural network

\begin{tabular}{|c|c|}
\hline \multicolumn{2}{|c|}{ Abbreviations } \\
\hline $\mathrm{C}_{0}$ & $\begin{array}{l}\text { Initial concentration of arsenic in the solution } \\
(\mathrm{mg} / \mathrm{L})\end{array}$ \\
\hline $\mathrm{C}_{\mathrm{e}}$ & $\begin{array}{l}\text { Equilibrium concentration of arsenic in the } \\
\text { solution }(\mathrm{mg} / \mathrm{L})\end{array}$ \\
\hline $\mathrm{H}$ & Number of nodes in the hidden layer \\
\hline I & Number of nodes in the input layer \\
\hline $\mathrm{i}$ & An index of data \\
\hline $\max \left(\mathrm{X}_{\mathrm{i}}\right)$ & $\begin{array}{l}\text { The maximum value of the ith observed } \\
\text { variable in the training data-set }\end{array}$ \\
\hline $\min \left(\mathrm{X}_{\mathrm{i}}\right)$ & $\begin{array}{l}\text { The minimum value of the ith observed variable } \\
\text { in the training data-set }\end{array}$ \\
\hline $\max \left(Y_{i}\right)$ & $\begin{array}{l}\text { The maximum value of the ith observed } \\
\text { variable in the training data-set }\end{array}$ \\
\hline $\min \left(Y_{i}\right)$ & $\begin{array}{l}\text { The minimum value of the ith observed variable } \\
\text { in the training data-set }\end{array}$ \\
\hline $\mathrm{N}$ & The number of data points \\
\hline $\mathrm{n}$ & Number of observations \\
\hline $\mathrm{R}_{\mathrm{e}}$ & Removal efficiency $(\%)$ \\
\hline $\mathrm{t}$ & The target (experimental) data \\
\hline $\mathrm{X}_{\mathrm{im}}$ & Observed value of the ith variable \\
\hline $\mathrm{X}_{\mathrm{i}}($ net $)$ & Normalized value of the ith variable \\
\hline$Y_{i(p)}$ & The predicted value of the ith output variable \\
\hline $\mathrm{y}$ & The predicted value \\
\hline
\end{tabular}

\section{Introduction}

Bearing in mind the ubiquitous nature of arsenic in the environment, human exposure to arsenic is unavoidable (Mondal et al. 2006). Globally, the degree of non- 
occupational exposure to arsenic differs significantly; depending on the local geochemistry and the level and vicinity of anthropogenic activities such as smelting, petroleum refining, mining, herbicide and pesticide application and burning of fossil fuels (Mondal et al. 2006; Pillewan et al. 2011). Copper smelting creates a huge volume of wastewater containing large amounts of inorganic compounds such as heavy metals like lead, copper, zinc, iron, cadmium and bismuth and highly carcinogenic metalloid like arsenic species, poses a serious threat towards man, and the flora and fauna of our ecosystem contaminating the natural water tables (ground water and surface water) in the vicinity. In copper smelting wastewater the concentration of arsenic is as high as $1979 \mathrm{mg} / \mathrm{L}$ (Basha et al. 2008). With the aim of maintaining a good quality of fresh water resources, this wastewater must be treated so that the water can be reverted back to the ecosystems. Long-term exposure to arsenic contaminated water results in bladder, liver, kidney, skin and lung cancer as well as loss of appetite, pigmentation changes, muscular weakness, nausea and neurological disorders (Mandal and Suzuki, 2002). Arsenic in drinking water mainly exists as arsenite $[\mathrm{As}(\mathrm{III})]$ or arsenate $[\mathrm{As}(\mathrm{III})]$. This is a matter of huge concern since As(III) is 25-60 fold more toxic and more mobile than As(V) (Morrison et al. 1989).

On the basis of investigation of the fatal effect of arsenic on human body, the maximum contaminant level (MCL) of arsenic in drinking water has been revised from 50 to $10 \mu \mathrm{g} / \mathrm{L}$ by the World Health Organization (WHO) in 1993 (WHO 1993) and the European Commission in 2003 (European commission Directive, 98/83/EC 1998). For implementing such a stricter MCL needs the development of simple, lucrative methods for the removal of arsenic from water or wastewater.

The techniques applied in the treatment of wastewater or contaminated water are generally categorized into three categories-physical (membrane processes, ion exchange, adsorption, electrocoagulation, electrochemical), chemical (oxidation-precipitation, coagulation) and biological (US EPA 2000; Mondal et al. 2006; Mohan and Pittman 2007). These can be carried out separately or in combination, depending on the level and category of contamination. With the purpose of achieving the estimated levels of contaminant removal, separate wastewater treatment techniques are assembled into a variety of systems, categorized as primary, secondary and tertiary wastewater treatments. Generally, both physical and chemical approaches are expensive and are not suitable for small-scale industries (Kundu and Gupta 2006; Singh and Pant 2006). Furthermore, most chemical methods increase the conductivity, $\mathrm{pH}$ and overall load of dissolved matter in the wastewater. In this respect, biological or biotreatment of wastewater is an amended choice (Renuka et al. 2015). Bioremediation as an alternative and green technology becomes encouraging for remediating the environmental contaminations (Kumari et al. 2006). It has several advantages such as outstanding performance, environmental friendly, possible recycling and low operational and maintenance cost to remediate arsenic from contaminated water (Zhang et al. 2008). However, issues related to disposal of sludge and dewatering have made researchers to find out other alternatives. The most general biological wastewater treatment practiced in the treatment of municipal and industrial wastewaters is the usage of activated sludge only (Radjenovic et al. 2009) or in combination with algae (Su et al. 2012). Over the last few years, it is tried to apply intensive microalgal cultures for performing the biological tertiary treatment of secondary wastewater (Oswald and Gottas 1957; De la Noüe et al. 1992).

Phycoremediation, the use of plants (including algae or lower plants for environmental clean-up) and associated microflora for the removal or biotransformation of contaminants containing nutrients, heavy metals, etc. from wastewater and $\mathrm{CO}_{2}$ from waste air. It seems to be an encouraging choice as a cost effective, non-invasive alternative to the currently available physicochemical contaminant remediation methods (Olguín 2003; Franchino et al. 2013; Richards and Mullins 2013). Wastewater treatment with microalgae or macroalgae, stated to as phycoremediation, is a term coined currently by John (2000). Remediation by algae is taken as a feasible choice for metal ion remediation leading to the improvement of water quality and sustainable development of aquatic systems (Kumar et al. 2007). The accumulation of heavy metals in algae includes two different methods, an initial rapid (passive) uptake followed by a much slow (active) uptake (Cho et al. 1994). During the passive uptake, metal ions are adsorbed on the cell surface within a comparatively short span of time (Gupta et al. 2006). However, active uptake of metals which is dependent on cell metabolism, results into transport of metal ions across the cell membrane (Raungsomboon et al. 2008; Chakraborty et al. 2011). Generally, various functional groups such as hydroxyl, amino, carboxyl, sulfhydryl, phosphoryl, etc. exist on the cell surface (Chojnacka et al. 2005). Microalgae play an important role in controlling metal ion concentration, since their functional ion that is located on the cell wall are able to bound ionic metal (Volesky 2007); sink or remove it by accumulation, adsorption or metabolization into substantial level (Priyadarshani et al. 2011).

Microalgae are superior in remediation methods because various toxic substances, as well as other wastes can be treated with algae and most significantly they are nonpathogenic. The menace of accidental discharge of contaminants into the atmosphere instigating human health and environmental issues can be escaped while algae are used to remediate. Algae use the wastes as nutritional sources 
and enzymatically degrade the contaminants. Metal ions and xenobiotics are recognized for being transformed/ detoxified/or volatilized by algal metabolism (Muthukumaran et al. 2005). Algal growth can retain the water clean and make natural water more appropriate for human ingestion. As microalgae use $\mathrm{CO}_{2}$ as a carbon source, they can grow photoautotrophically without the adding an organic carbon source (Rao et al. 2011). Phycoremediation is mostly eye-catching since it has the capability for dealing with more than one problem on-site. The cultivation of algae in wastewater offers the combined advantages of treatment of the wastewaters, mitigation of greenhouse gases and at the same time creating algal biomass. This biomass can be used for multiple applications such as bioenergy resources (biogas and biofuels), food additives and protein supplements (human and animal feed), bio-ore for precious heavy metals, fertilizer, cosmetics, pharmaceuticals and other valued chemicals (Priyadarshani et al. 2011; Kumar et al. 2013; Sahu et al. 2013). The drawbacks of using microalgae for metal ion remediation are the requirement of energy for drying while using dead microalgae, necessity for being immobilized and has restricted use in the batch systems (Brinza et al. 2007), its small size, low mass index are easily degraded by microorganism (Soeprobowati and Hariyati 2013). It has been recommended that a living species shows better biosorption of metals than dead biomass, probably because of effective membrane binding and metabolic energy-dependent intracellular uptake (Terry and Stone 2002; Doshi et al. 2007). The selection of microalgae for being used in wastewater treatment is done by their robustness against wastewater and by their competence for growing in and taking up nutrients from wastewater (Olguín 2003).

ANN is one of the non-conventional tools based on data to model the adsorption phenomenon. Few investigators tried to develop an assessment of ANN as one valuable approach for predicting and simulating the removal process. Examples for application of AANs in water treatment are removal of arsenic by the modification of solid waste vegetable oil industry with Fenton reagent (FMSWVOI) (Jaafarzadeh et al. 2012), removal of $\mathrm{Zn}$ (II) ions from leachate by hazelnut shell (Turan et al. 2011a), adsorption of $\mathrm{Cu}$ (II) from industrial leachate by pumice (Turan et al. 2011b) and removal of lead ions by Nigella sativa seeds (black cumin) (Bingöl et al. 2012). ANN methods were compared because of their generalization and predictive abilities, sensitivity analysis as well as optimization efficiency in metal ion removal from wastewater (Turan et al. 2011a, b; Bingöl et al. 2012).

This paper explores the possibility of using living microalgae Chlorella pyrenoidosa for phycoremediation of arsenic-enriched water. Although a number of pioneering works have been reported on treatment of arsenic containing wastewater by various techniques, only a few studies on a microbial route for detoxification of arsenic has been reported so far. Algae can influence copper smelting wastewater in different ways such as: (1) Metal biosorption into the cell wall; (2) metal complex formation by EPS; (3) natural alkalinity generation and metal hydroxide precipitation; (4) biomass and EPS as nutrient source for SRB (Das et al. 2009).

The effects of various operational parameters such as initial $\mathrm{pH}$, inoculum size, contact time and initial arsenic concentration (either $\mathrm{As}(\mathrm{III})$ or $\mathrm{As}(\mathrm{V})$ ) on the removal of arsenic (either As(III) or As(V)) were also examined. The species can be used for the treatment of arsenic-enriched water reject with sewage in an algal pond. Based on phycoremediation experiments, ANN model for predicting the removal efficiency of both $\mathrm{As}(\mathrm{III})$ and $\mathrm{As}(\mathrm{V})$ of $C$. pyrenoidosa used as a phycoremediator, was applied in this investigation. Phycoremediation of arsenic (either $\mathrm{As}(\mathrm{III})$ or $\mathrm{As}(\mathrm{V})$ ) ions from wastewater is optimized for determining the optimal network structure. Finally outputs acquired from the ANN models were compared with the experimental results. Advantages and then additional expansions were too deliberated.

\section{Materials and methods}

\section{Microalgae and culture medium}

C. pyrenoidosa was collected from Department of Biotechnology, IIT Roorkee and grown in BG11 culture medium (without adding carbon source) (Park et al. 2011; Yadavalli and Heggers 2013).The composition of BG11 media are given in Tables 1 and 2 as follows:

\section{Preparation of living cells of $C$. pyrenoidosa}

The culture was initially grown in BG11 growth media in a $250 \mathrm{~mL}$ round bottom flask closed with cotton plug as follows:

Table 1 Major elements

\begin{tabular}{ll}
\hline Composition & Quantity (per L) \\
\hline $\mathrm{NaNO}_{3}$ & $1.5 \mathrm{~g}$ \\
$\mathrm{~K}_{2} \mathrm{HPO}_{4}$ & $0.04 \mathrm{~g}$ \\
$\mathrm{MgSO}_{4} \cdot 7 \mathrm{H}_{2} \mathrm{O}$ & 0.075 \\
$\mathrm{CaCl}_{2} \cdot 2 \mathrm{H}_{2} \mathrm{O}$ & 0.036 \\
$\mathrm{Citric}$ acid & $0.006 \mathrm{~g}$ \\
$\mathrm{Na}_{2} \mathrm{EDTA}$ & $0.001 \mathrm{~g}$ \\
$\mathrm{Na}_{2} \mathrm{CO}_{3}$ & $0.02 \mathrm{~g}$ \\
Ferric ammonium citrate & $0.006 \mathrm{~g}$ \\
Trace metal mix A5 & $1.0 \mathrm{~mL}$
\end{tabular}


Table 2 Trace metal mix A5

\begin{tabular}{ll}
\hline Composition & Quantity (per $100 \mathrm{~mL})$ \\
\hline $\mathrm{H}_{3} \mathrm{BO}_{3}$ & $2.86 \mathrm{mg}$ \\
$\mathrm{MnCl}_{2} \cdot 4 \mathrm{H}_{2} \mathrm{O}$ & $1.81 \mathrm{mg}$ \\
$\mathrm{ZnSO}_{4} \cdot 7 \mathrm{H}_{2} \mathrm{O}$ & $0.22 \mathrm{mg}$ \\
$\mathrm{Na}_{2} \mathrm{MoO}_{4} \cdot 2 \mathrm{H}_{2} \mathrm{O}$ & $0.39 \mathrm{mg}$ \\
$\mathrm{CuSO}_{4} \cdot 5 \mathrm{H}_{2} \mathrm{O}$ & $0.08 \mathrm{~g}$ \\
$\mathrm{Co}\left(\mathrm{NO}_{3}\right)_{2} \cdot 6 \mathrm{H}_{2} \mathrm{O}$ & $0.05 \mathrm{~g}$ \\
\hline
\end{tabular}

The algal strain was first grown in the round bottom flask. To do so, the algal inoculum was prepared by transferring a loop full of algal culture aseptically from the nutrient agar plates supplied by Department of Biotechnology of Indian Institute of Technology, Roorkee, to the round bottom flask consisting of growth medium (sterilized at $121{ }^{\circ} \mathrm{C}$ temperature, 15 psi pressure for at least $15 \mathrm{~min}$ ), incubated at $28{ }^{\circ} \mathrm{C}$ for 7 days in a thermostatically controlled environmental chamber (PGC-292, plant growth chamber, Ambala, India). The $\mathrm{pH}$ of the growth medium was adjusted to 9.0 with $1 \mathrm{~N} \mathrm{HCl}$ and $1 \mathrm{~N} \mathrm{NaOH}$ before inoculation. Then, the microalgal strain was grown on a petri plates consisting of agar medium containing the nutrient components (Tables 1 and 2) and agar (12.0 g/L). The microalgae were inoculated from the plates on another fresh agar plate after the incubation of cultures at $28{ }^{\circ} \mathrm{C}$ for 7 days in agar plates and stored at $4{ }^{\circ} \mathrm{C}$ till required for further studies.

\section{Preparation of arsenic-enriched water}

All chemicals used were of analytical reagent grade, procured from Himedia Laboratories Pvt. Ltd. Mumbai India. Arsenic stock solution was prepared using salts of $\mathrm{NaAsO}_{2}$ and $\mathrm{Na}_{2} \mathrm{HAsO}_{4}, 7 \mathrm{H}_{2} \mathrm{O}$ in double distilled water (APHA 1998). BG11 growth media composition as mentioned in Appendix A-8 was also added into the synthetic solution. Then, the prepared phycoremediation media without or with arsenic [either $\mathrm{As}(\mathrm{III})$ or $\mathrm{As}(\mathrm{V})]$ ions was subjected to autoclave sterilization at 15 psi pressure and at $120^{\circ} \mathrm{C}$ for $15 \mathrm{~min}$. The $\mathrm{pH}$ of the phycoremediation media was adjusted to the requisite value by dropwise addition of sterile $1 \mathrm{~N} \mathrm{HCl}$ and $1 \mathrm{~N} \mathrm{NaOH}$ solution.

\section{Experimental set-up}

Experiments were arranged for investigating the scavenging of either $\mathrm{As}(\mathrm{III})$ or $\mathrm{As}(\mathrm{V})$ by growing microalgae $C$. pyrenoidosa in different concentrations of arsenic-enriched water. BG11 medium was served as control. An optimum aliquot (10\%, volume of inoculum/volume of growth medium) of preculture was harvested aseptically during the exponential growth phase (OD value $\sim 0.473$ at $680 \mathrm{~nm}$ ) and it was transferred to the fresh media $(100 \mathrm{~mL})$ supplemented with arsenic [either $\mathrm{As}(\mathrm{III})$ or $\mathrm{As}(\mathrm{V})]$ of necessary amount for different studies in $250 \mathrm{~mL}$ Erlenmeyer flasks. Thermostatically controlled environmental chamber was sustained at $28{ }^{\circ} \mathrm{C}$ temperature. Illumination was supplied by continuous cool white fluorescent lamps at $2000 \mathrm{~L} \times$ (Philips $40 \mathrm{~W}$, cool daylight, $6500 \mathrm{~K}$ ) with a dark/light period of 12:12 h. The experiments were carried out for $360 \mathrm{~h}$ and all tests were done in duplicate (Fluid Particle Research Lab).

The amount of adsorbate molecules removed in terms of percentage was calculated as follows:

\%removal $=\frac{\left(C_{o}-C_{e}\right)}{C_{o}} \times 100$

\section{Arsenic analysis}

The cultures were incubated for $360 \mathrm{~h}$ and $5 \mathrm{~mL}$ culture was withdrawn from each flask (control and treated) under sterilized conditions after fixed time intervals. The cultures were centrifuged at $5000 \mathrm{rpm}$ for $5 \mathrm{~min}$ (REMI, India) and then supernatants were diluted with $\mathrm{HNO}_{3}$ solution $(10 \%$, $\mathrm{v} / \mathrm{v})$. Finally the prepared sample was preserved in a frozen state, till quantification of arsenic was done. The supernatant was analysed for determination of arsenic concentration using ThermoFisher Scientific iCE 3000 Series AA graphite furnace atomic absorption (GFAA) spectrometer (detection limit $20 \mu \mathrm{g} / \mathrm{L}$ ).

\section{Modelling technique}

\section{Artificial neural network modelling}

ANNs were previously established from the primary conception of artificial intelligence that work for simulating the process of nervous system and human brain (Chairez et al. 2009; Rene et al. 2009; Ekici and Aksoy 2010). Actually an artificial neural network (ANN) is an enormously interconnected network structure comprising of several simple processing elements proficient of executing parallel computation for data processing. This technique is valuable where the complication of the mechanisms indicating performance of process is very high (Turan et al. 2011a, 2011b).They comprise a chain of mathematical correlation which are utilized for simulating the learning and memorizing operation. ANNs learn by example in which an actual measured input variables set and analogous outputs are offered for determining the guidelines that manage the relationship between the variables (Chairez et al. 2009). ANNs are taken into account to be commanding for apprehending the non-linear effect and are 
practically valid to each and every single situation in which a relationship although extremely non-linear existing between the dependent and independent variables (Elias et al. 2006). In current years artificial neural networks (ANNs) have been broadly considered for solving the environmental problems owing to their dependable and noticeable features to capture the non-linear relationships present between variables (Turan et al. 2011a, b). It can be used for solving problems that are not suitable for conventional statistical methods. ANNs have been deliberated owing to extensive range of use and their competence and capacity for solving complex problems. Process modelling and simulation particularly when no analytical model are present, are the applications of ANNs at chemical engineering (Turan et al. 2011a, b; Jaafarzadeh et al. 2012).

The ANN architecture contains input layer, one or more hidden layers and output layer (Movagharnejad and Nikzad 2007). Each layer of the network contains a number of an interconnected processing element termed neurons. These neurons interact with each other with the aid of the weight. Each neuron is linked to all the neurons in the next layer. The architecture of network is exhibited as $1, \mathrm{~m}, \mathrm{n}$ where 1 neurons are exhibited at input layer (equal to the number of inputs in the network), $m$ neurons are exhibited at the hidden layer (optimized through experimentation) and $n$ neurons are exhibited at the output layer dependent onto number of outputs preferred from model (Rene et al. 2009; Giri et al. 2011). The hidden layers allow these networks for computing intricate relations between inputs and outputs. In this set of networks data moves in only one direction forward from the input layer to the hidden layer and then to the output. Running of neural network performed in three steps: (1) learning or training, (2) validation and (3) testing.

Input layer accepts data from the external sources and passes this data to the network for processing. Hidden layer accepts data from the input layer, performs all the data processing, output layer accepts processed data from the network and sends the consequences out to an external receptor. A layer of neurons is estimated by its weight matrix, a transfer function and a bias vector. The input signals are modified by interconnection weight recognized as weight factor $\left(\mathrm{W}_{\mathrm{ji}}\right)$, which signifies the interconnection of ith node of the first layer to $\mathrm{jth}$ node of the second layer. The sum of modified signals (total activation) is thereafter modified by a sigmoid transfer function (f). Likewise outputs signal of hidden layer are modified by interconnection weight $\left(\mathrm{W}_{\mathrm{ji}}\right)$ of kth node of output layer to jth node of hidden layer. The sum of the modified signal is thereafter modified by sigmoid transfer (f) function and output is collected at output layer (Giri et al. 2011; Mandal et al. 2015).

The number of hidden layers is to be chosen dependent onto the complication of the problem. Usually one hidden layer is adequate to explore maximum problems. The number of neurons in the hidden layer is chosen by trial and error method beginning from minimum and thereafter augmented reliant on the nature of problem (Gorashi and Abdullah 2012). The training of neural network is done by giving a run of input data and target output values. The parameters influencing target output should be chosen as input parameters. The back propagation training algorithm has been extensively utilized for modelling several problems in environmental engineering. In back-propagation training algorithm, neurons in the hidden layer and output layer processes its inputs by multiplying each input by its weight, adding the product and thereafter processing the addition using a non-linear transfer function, too termed activation function. The maximum common transfer function utilized is sigmoid function. The learning in neural network occurs by modifying weights of the neurons consistent with the error between the values of actual output and target output. The alterations in weights are proportional to the negative of the derivative of the error (Aghav 2011).

The training of ANN model is done by giving the whole input data-set to the network and sustained till the average MSE is minimized. After the training is finished, the trained neural network is estimated for reproducing the target output values for the training data. Weights of the trained neurons are thereafter stored in the neural network memory. The validation of the trained network is performed by giving the validation data-set and thereafter comparing the network output with the actual output values. The testing of the trained network is done by giving the test data-set and thereafter comparing the network output with the actual output values. The formulated ANN model performance can be estimated by numerous statistical parameters, for example, coefficient of determination $\left(\mathrm{R}^{2}\right)$. A well-trained model should have $\mathrm{R}^{2}$ value near to 1 and values of error terms should be negligible (Aghav 2011).

\section{ANN software}

The numbers of input and output neurons are fixed as said by the nature of the problem. In the current investigation, the training, validation and testing of ANN modelling was performed utilizing software MATLAB 7.6 (VersionR2008b) (MathWorks, Inc., USA) mathematical software by ANN toolbox. A neural network training tool (nntool) used for training of the network. In the current research a three-layer feed-forward Back propagation (BP) neural network have been used with a tangent sigmoid transfer function (tansig) at hidden layer and a linear transfer function (purelin) at output layer to predict and simulate phycoremediation capacity for removal of either As(III) or 
Table 3 Range of variables

\begin{tabular}{|c|c|c|c|c|c|}
\hline Sl. no. & Input variables & Number of runs & Ranges & Average, $R_{\mathrm{e}} \%$ & Standard deviation, $R_{\mathrm{e}} \%$ \\
\hline 1 & Initial $\mathrm{pH}$ & 11 & $2-12$ & 47.27 & 26.16 \\
\hline 2 & Inoculum size $(\% \mathrm{v} / \mathrm{v})$ & 10 & $2-20$ & 74.43 & 6.99 \\
\hline 3 & Contact time (h) & 18 & $4-360$ & 74.69 & 15.47 \\
\hline 4 & Initial arsenic concentration $(\mathrm{mg} / \mathrm{L})$ & 10 & $50-2000$ & 71.93 & 8.68 \\
\hline
\end{tabular}

As(V) (Aghav 2011; Mandal et al. 2015). The LevenbergMarquardt back propagation algorithm which was independently developed by Levenberg (1944) and Marquardt (1963), (LMA) was applied for training of the network as the best algorithm. Total iteration number was set at 3000 for all learning algorithms and the performance goal is set at $10^{-5}$ (Turan et al. 2011b). The number of nodes in the hidden layer $(\mathrm{H})$ is described by the relation as follows (Giri et al. 2011; Mandal et al. 2015):

$H=2 \sqrt{(I+1)}$

\section{Data division}

The input layer relates to the four experimental parameters comprising the initial $\mathrm{pH}$, inoculum size (\% v/v), contact time (h), initial arsenic concentration [either As(III) or $\mathrm{As}(\mathrm{V})](\mathrm{mg} / \mathrm{L})$. The output layer was the \% removal of arsenic [either As(III) or As(V)]. The experiments were repeated two times for enhancing the reliability and the average values were taken. The experimental design utilized in the present study was on the basis of one factor experiment at a time. The data and their related statistics are presented in Table 3.

Data points of \% removal were thereafter interpolated by utilizing a cubic spline curve fitting (CSCF) technique (Turan et al. 2011a, b). The major reason of utilizing the CSCF technique is for increasing data points between minimum $\mathrm{R}_{\mathrm{e}} \%$ and maximum $\mathrm{R}_{\mathrm{e}} \%$. The motivation of employing the CSCF technique is that it is simple for implementing and for producing a curve that looks to be seamless. The least square curve fitting approach inclines for building in distortions near the first and the last samples. But CSCF dodges this phenomenon. Data points were set to 227 and then the data points were divided into training, validation and test sets with a ratio of 60,20 and $20 \%$, respectively. Fig. S1 of supplementary materials exhibits the overall flowchart for arsenic [either As(III) and As(V)] removal system.

\section{Data preprocessing}

The input and output variables in the current investigation had various features and importance-level ensuing into varied response to the neural network. The ANN model training would be more effective if preprocessing steps are carried out onto the input and target data, and therefore, the preprocessing implementation is utilized in real application. All the data (input and output) were normalized between 0.1 and 0.9 for avoiding numerical overflows because of very large or small weights. The preprocessing of the data could be carried out by the algorithm as given in Eq. (3) (Giri et al. 2011; Mandal et al. 2015):

$X_{i}($ net $)=0.1+0.8 \frac{\left(X_{i m}-\min \left(\mathrm{X}_{\mathrm{i}}\right)\right)}{\max \left(X_{i}\right)-\min \left(X_{i}\right)}$

New inputs are fed into the trained networks after preprocessing of the training set-data and thereafter are processed with the maximum and minimum vectors that are computed for the training data-set. With the purpose of comparing the consequences of neural network with the observed values, the rescaled output necessities to be transformed back within the similar range for the original target output values. The algorithm as presented in Eq. (4) was utilized for this reason:

$Y_{i(p)}=\min Y_{i}+\frac{\left(\max \left(Y_{i}\right)-\min \left(Y_{i}\right)\right)}{0.8} \times\left(X_{i}(n e t)-0.1\right)$

\section{Optimization of the ANN structure}

There are no universal strategies to choose the architecture and algorithm of ANN for solving a practical problem. For finding the optimum number of neurons $(\mathrm{N})$ in the hidden layer trial and error method was utilized. For simulation of individual parameter, the number of the neurons in hidden layer was varied from 1 to 12 . Too many neurons can lengthen the time required for training the network, whereas too few may not be adequate to train it at all. The selection of the number of neurons in the hidden layer is frequently the consequence of empirical tests coupled with trial and error.

In the current study mean square error (MSE) was selected for measuring the network performance of Models 'A' (C. pyrenoidosa and As(III) system) and 'B' $(C$. pyrenoidosa and $\mathrm{As}(\mathrm{V})$ system). The condition for choice of the optimum ANN structure is the mean square error (MSE) the test data, as well as the correlation coefficient $\left(R^{2}\right)$ which can be demarcated as follows (Turan et al. 2011a, b; Bingöl et al. 2012): 
$M S E=\frac{1}{N} \sum_{i=1}^{N}\left(t_{i}-y_{i}\right)^{2}$

$R^{2}=1-\frac{\sum_{i=1}^{N}\left(t_{i}-y_{i}\right)^{2}}{\sum_{i=1}^{N}\left(y_{i}\right)^{2}}$

The assessed results presented here are those of minimum errors. Moreover, with the purpose of examining the network response in more details, a linear regression analysis too was performed with respect to network forecasted values and actual experimental values of contaminant removal efficiencies for all the two developed models.

The SD used in the present study was determined using the following formula [99]:

$\mathrm{SD}=\sqrt{\frac{\sum(x-y / x)^{2}}{(n-1)}}$

\section{Results}

\section{Effect of initial $\mathrm{pH}$ on phycoremediation properties of $C$. pyrenoidosa}

The $\mathrm{pH}$ is one of the significant factors that considerably influences the adsorbate ion speciation, the chemistry of solution, interaction between adsorbate and adsorbent and surface charge of adsorbent surface (Basha et al. 2009; Dash et al. 2009). Hence, the effect of $\mathrm{pH}$ on phycoremediation of $\mathrm{As}(\mathrm{III})$ and $\mathrm{As}(\mathrm{V})$ by microalgae was monitored by changing the initial $\mathrm{pH}$ of the solution in the range of 2.0-12.0. In the present study, the term phycoremediation is used to describe any of these possible modes of interactions (passive uptake and active uptake) between the metal ion and the surface of the cells without distinction. From Fig. 1a, b, it was evident that the phycoremediation $\%$ of both $\mathrm{As}(\mathrm{III})$ and $\mathrm{As}(\mathrm{V})$ were higher in basic media than in acidic media and the highest removal was found at $\mathrm{pH}$ 9.0. This may be attributed to the favourable growth of C. pyrenoidosa biomass in alkaline media $\mathrm{pH}$ (i.e. $\mathrm{pH}$ 9.0).

The phycoremediation of both $\mathrm{As}(\mathrm{III})$ and $\mathrm{As}(\mathrm{V})$ varied significantly depending upon the arsenic species also. The difference in the phycoremediation \% of As(III) and $\mathrm{As}(\mathrm{V})$ could be elucidated on the basis of the charge on the species of arsenic and the surface charges of the microalgal biomass.

It was agreed from Fig. 1a, b that the phycoremediation of both $\mathrm{As}(\mathrm{III})$ and $\mathrm{As}(\mathrm{V})$ ions (13.913 and 15.846\%, respectively) were very poor in the $\mathrm{pH}$ range $<3.0$. With the increase in $\mathrm{pH}$ from 3.0 to 9.0 , there was a significant increase in the phycoremediation of both As(III) and $\mathrm{As}(\mathrm{V})$ ions. The highest phycoremediation \% of As(III)

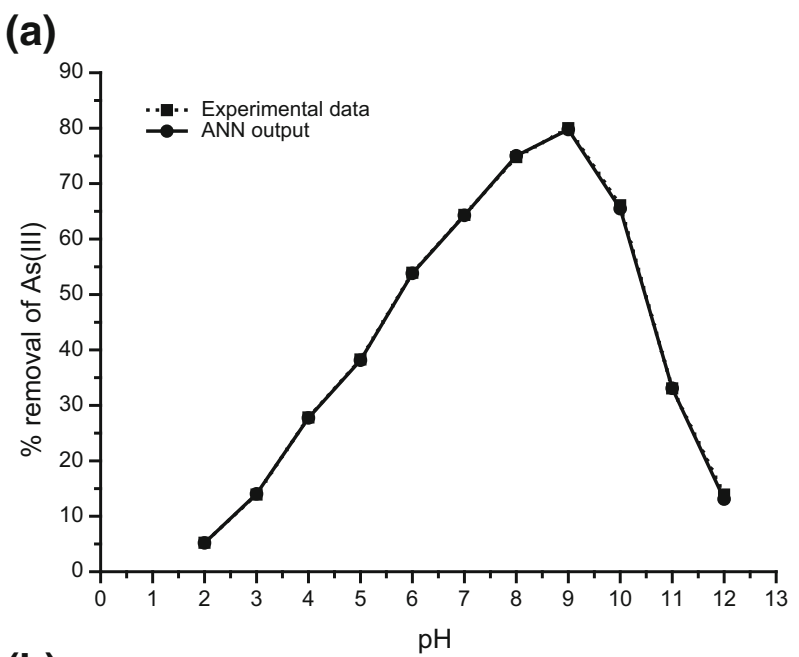

(b)

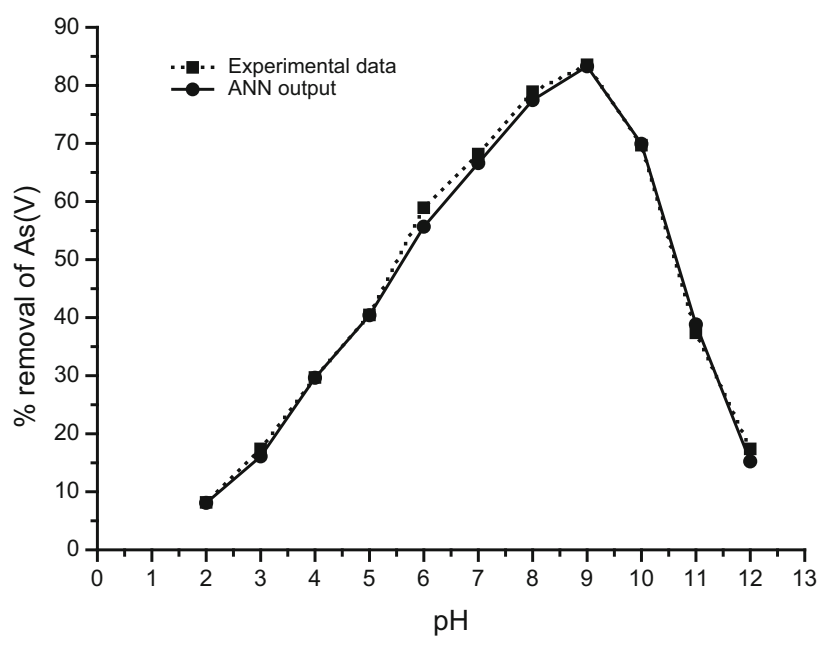

Fig. 1 Experimental data and ANN outputs as a function of $\mathrm{pH}$ versus (\%) removal of a $\mathrm{As}(\mathrm{III})$ and $\mathbf{b} \mathrm{As}(\mathrm{V})$ by Chlorella pyrenoidosa (experimental conditions: inoculum size $(\% \mathrm{v} / \mathrm{v}): 10$; contact time: $144 \mathrm{~h}$; initial arsenic concentration: $50 \mathrm{mg} / \mathrm{L}$; temperature: $28{ }^{\circ} \mathrm{C}$ )

and $\operatorname{As}(\mathrm{V})$ ions were achieved as 80 and 83.538 , respectively, at $\mathrm{pH}$ 9.0. Then, a sharp decrease in the phycoremediation was found and $\mathrm{As}(\mathrm{V})$ exhibited more phycoremediation than As(III). These results can be understood from the following explanations.

In the $\mathrm{pH}$ range of 2.0-9.0 and 10.0-12.0, As(III) exists generally in neutral $\left(\mathrm{H}_{3} \mathrm{AsO}_{3}\right)$ and anionic $\left(\mathrm{H}_{2} \mathrm{AsO}_{3}{ }^{-}\right)$ forms, respectively. Reports also approve that $\mathrm{As}(\mathrm{V})$ exists mostly in the monovalent form of $\mathrm{H}_{2} \mathrm{AsO}_{4}{ }^{-}$in the $\mathrm{pH}$ range 3.0-6.0, yet at $\mathrm{pH}$ near 2.0, a small extent of $\mathrm{H}_{3} \mathrm{AsO}_{4}$ also remains. However, a divalent anion $\mathrm{HAsO}_{4}{ }^{2-}$ prevails at higher $\mathrm{pH}$ values $(>8.0)$; both species co-exist in the intermediate region of pH 6.0-8.0 (Ranjan et al. 2009).

Also at low $\mathrm{pH}$ 1.0-6.0, the density of hydrogen ion was quite high against $\mathrm{As}(\mathrm{III})$ and $\mathrm{As}(\mathrm{V})$ ions, which resulted in 
protonation of the components of the cell wall, i.e. the surface of microalgae $C$. pyrenoidosa biomass. Thus, the amine and hydroxyl group in the surfaces of microalgal biomass were vastly protonated in acidic conditions. The protonation of microalgal cell wall moieties reduced the phycoremediation efficiency because there was a strong electrostatic interaction remains between positively charged surface of the biomass and oxyanions (Boddu et al. 2008; Velásquez and Dussan 2009). Comte et al. (2008) described that the deprotonated form of the reactive sites in cell wall, generally amino, phosphoric and carboxylic groups, is mainly responsible for the metal ions binding to EPS. Chojnacka et al. (2005) also stated that various functional groups of cell wall of microalgal biomass are responsible for binding of metal ions. The solution $\mathrm{pH}$ influences the ionization state of these functional groups. Anions could be anticipated to interact more strongly with cells as the concentration of positive charges increases.

The surfaces of microalgal biomass are vastly protonated in extreme acidic conditions and such a condition is not so encouraging for removal of $\mathrm{As}(\mathrm{III})$ and $\mathrm{As}(\mathrm{V})$ due to the presence of neutral As(III) and As(V) species in this range, resulting in virtually less change in the phycoremediation within the $\mathrm{pH}$ range 2.0-4.0. The degree of protonation of the surface decreases progressively, with the increase in $\mathrm{pH}$ of the system. The highest phycoremediation of $\mathrm{As}(\mathrm{V})$ was found at $\mathrm{pH} 9.0$ where the prevailing species of $\mathrm{As}(\mathrm{III})$ was only non-ionic species $\mathrm{H}_{3} \mathrm{AsO}_{3}$ (Smedley and Kinniburgh 2002), might be attributed to several products of undetermined reaction during the process of phycoremediation. The neutral $\left(\mathrm{H}_{3} \mathrm{AsO}_{3}\right)$ and monoanionic $\left(\mathrm{H}_{2} \mathrm{AsO}_{3}{ }^{-}\right)$species are thus considered to be responsible for the phycoremediation of $\mathrm{As}(\mathrm{III})$, also due to the substitution of hydroxyl ions or water molecules. The neutral species $\left(\mathrm{H}_{3} \mathrm{AsO}_{3}\right)$ cannot undergo electrostatic interaction with the microalgal biomass. However, such species can interact with the unprotonated amino groups (Aryal et al. 2010; Prasad et al. 2013). At pH 5.0-9.0, anionic species of $\mathrm{As}(\mathrm{V})\left(\mathrm{H}_{2} \mathrm{AsO}_{4}{ }^{-}\right.$and $\left.\mathrm{HAsO}_{4}{ }^{2-}\right)$ exists and the surface of microalgal biomass is also protonated and so a strong electrostatic interaction remains between positively charged microalgal biomass surface and oxyanions and as a result the removal improved in this $\mathrm{pH}$ range because of the increase in $\mathrm{HAsO}_{4}{ }^{2-}$ species with the increase in $\mathrm{pH}$ of the solution. The dominant species of $\mathrm{As}(\mathrm{V})$ in the above-mentioned $\mathrm{pH}$ range are $\mathrm{H}_{2} \mathrm{AsO}_{4}{ }^{-}$ions, which can be phycoremediated on the microalgal biomass by substituting hydroxyl ions or coordination of hydroxyl groups with the microalgal biomass (Boddu et al. 2008; Prasad et al. 2013). So, the highest removal of $\mathrm{As}(\mathrm{V})$ was found to be at $\mathrm{pH} 9.0$.

With the increase in $\mathrm{pH}$ of the system, the degree of protonation of the surface decreased gradually. As the $\mathrm{pH}$ of the solution increased more than 9.0 (alkaline medium), the negatively charged species $\mathrm{H}_{2} \mathrm{AsO}_{3}{ }^{-}$and $\mathrm{H}_{2} \mathrm{AsO}_{4}{ }^{2-}$ started to govern in the medium and cell surface also inclines to gain negative charges $\left(\mathrm{OH}^{-}\right)$(Volesky and Holan 1995; Sadowski 2001) resulting in the reduction of phycoremediation of both $\mathrm{As}(\mathrm{III})$ and $\mathrm{As}(\mathrm{V})$ (Ranjan et al. 2009). This process can be defined in three stages: (1) the decline may be because of the negatively charged adsorbate by accumulating hydroxyl ions $\left(\mathrm{OH}^{-}\right)$on the surface of microalgal biomass, (2) may be because of the ionization of very weak acidic functional groups of the microalgal biomass, or both at higher $\mathrm{pH}$ values, and/or (3) a repulsive force may exist between the anionic species and the negatively charged surface of the microalgal biomass (Ranjan et al. 2009; Giri et al. 2011, 2013). This results in reduced $\mathrm{As}(\mathrm{III})$ and $\mathrm{As}(\mathrm{V})$ removal at higher $\mathrm{pH}$ values (Ranjan et al. 2009).

More attraction among the $\mathrm{As}(\mathrm{V})$ ions and $\mathrm{H}^{+}$ions on the surface of microalgal biomass may be the motive for the maximum $\mathrm{As}(\mathrm{V})$ phycoremediation at $\mathrm{pH} 9.0$ compared to As(III).

Arsenic occurs in various oxidation states and the stability of these ionic species are influenced by the $\mathrm{pH}$ of the aqueous system. The mechanism of any phycoremediation process is very significant section to understand the characteristics of the microalgae and also to understand the process, which supports to design unique microalgae for future uses. A mechanism for the phycoremediation of $\mathrm{As}(\mathrm{III})$ and $\mathrm{As}(\mathrm{V})$ ions by ion exchange using $C$. pyrenoidosa biomass was suggested by taking the results acquired from the experimental studies (Fig. 1a, b).

The agreement between the experimental results and the ANN model predictions as a function of initial $\mathrm{pH}$ is shown in Fig. 1a, b. From this plot it can be understood that acquired outcomes from the recommended ANN model are in good agreement with the experimental results.

There are various mechanisms of interaction between the microalgae cells and metal ions: adsorption by physical forces, ion exchange, chelation, reduction, complexation, and microprecipitation, the plasma membrane and heavy metal flux, metallothioneins, phytochelatins (PCs), sequestration and compartmentalization in the vacuole, polyphosphate bodies in microalgae, sequestration to the chloroplast and mitochondria, and ion entrapment in interand intrafibrillar capillaries and spaces of the structural polysaccharidic network of external cell layers (Razmovzki and Sciban 2008; De Philippis and Micheletti 2009; Kumar et al. 2015). Chojnacka et al. (2005) and Monteiro et al. (2012) stated that the microalgal cell wall consisted mainly of peptidoglycan, polysaccharides, proteins, teichoic acid, and teichuronic acid, and lipids which offer various functional groups, like hydroxyl, carboxyl, sulfydryl, amine, or 
phosphate. Microalgae play an important role in controlling heavy metals concentration, since their functional groups that located on the cell wall, are capable to bound ionic metal (Volesky 2007; Kumar et al. 2015); sink or remove it by accumulation, biosorption or metabolization into substantial level (Priyadarshani et al. 2011).

Regarding the metal uptake into the cells, it can be nonspecific or with high substrate specificity; the first one being faster and driven by the chemiosmotic gradient across the cytoplasmic membrane, and the second one is driven by ATP as the energy source (Baptista and Vasconcelos 2008). Regarding the detoxification mechanisms, once the metals have been absorbed into the cells, they could be related to a tolerance response or to a real resistance mechanism (Arunakumara and Zhang 2008). One of the best considered responses to exposure of toxic heavy metal in microalgae is the phytochelatin synthesis induction. Various microalgal species respond to stress of heavy metal by phytochelatins synthesis (Hu et al. 2001; Pinto et al. 2003). Phytochelatins are mainly glutathione polymers which are 2-9 units in length, have great selectivity for only a few heavy metals comprising arsenic, lead, copper, gold, cadmium, zinc, mercury and silver (Stillman 1995).

Surface sites are positively charged at lower $\mathrm{pH}$ of the medium and therefore attract negatively charged As(III) and $\mathrm{As}(\mathrm{V})$ by an electrostatic interaction or columbic force (Mashitah et al. 1999; Hansen et al. 2006). The surface of C. pyrenoidosa biomass fulfils the coordination shells with the prevailing $\mathrm{OH}$ group with the materials under hydration. On the variation of $\mathrm{pH}$, these surface active $\mathrm{OH}$ groups may further bind or release $\mathrm{H}^{+}$where the surface remains positive because of the reaction:

1) The surface of $C$. pyrenoidosa would obtain a positive charge when $\mathrm{pH}$ was $<7.0$ because of the following reaction (Mondal et al. 2007; Mandal et al. 2011; Ren et al. 2012; Giri et al. 2013):

$$
\mathrm{MOH} \text { (surf) }+\mathrm{H}_{3} \mathrm{O}_{(\mathrm{aq})}^{+} \rightarrow \mathrm{MOH}_{2}^{+}+\mathrm{H}_{2} \mathrm{O} \text { (6.135) }
$$$$
\mathrm{MNH}_{2} \text { (surf) }+\mathrm{H}_{3} \mathrm{O}_{(\mathrm{aq})}^{+} \rightarrow \mathrm{MNH}_{2}{ }^{+}+\mathrm{H}_{2} \mathrm{O} \text { (6.136) }
$$

When $\mathrm{pH}>7.0$, a negative charge had been developed on the surface of $C$. pyrenoidosa:

$$
\mathrm{MOH}_{(\text {surf }}+\mathrm{OH}^{-}{ }_{(\text {aq })} \rightarrow \mathrm{M}-\mathrm{O}^{-}+\mathrm{H}_{2} \mathrm{O} \text { (6.137) }
$$$$
\mathrm{MNH}_{2 \text { (surf) }}+\mathrm{OH}^{-} \text {(aq) } \rightarrow \mathrm{M}-\mathrm{O}^{-}+\mathrm{H}_{2} \mathrm{O} \text { (6.138) }
$$

a) Thus, when $\mathrm{pH}<7.0$, the overall mechanism of $\mathrm{As}(\mathrm{III})$ or As(V) phycoremediation can be characterized in three different forms (Mandal et al. 2011; Giri et al. 2013):

(i) electrostatic interaction or coulombic interaction between positively charged centre (nitrogen, $\mathrm{OH}$ ) and negatively charged $\mathrm{As}(\mathrm{III})$ or $\mathrm{As}(\mathrm{V})$ in solution (Mandal et al. 2015):

$$
\begin{aligned}
& \mathrm{MNH}_{2}{ }^{+}+\mathrm{H}_{2} \mathrm{AsO}_{3}{ }^{-} \rightarrow \mathrm{MNH}_{2}^{+\cdots} \mathrm{H}_{2} \mathrm{AsO}_{3}{ }^{-}(6.139) \\
& \mathrm{MNH}_{2}{ }^{+}+\mathrm{H}_{2} \mathrm{AsO}_{4}{ }^{-} \rightarrow \mathrm{MNH}_{2}^{+\cdots} \mathrm{H}_{2} \mathrm{AsO}_{4}{ }^{-}(6.140) \\
& \mathrm{MNH}_{2}{ }^{+}+\mathrm{HAsO}_{3}{ }^{2-} \rightarrow \mathrm{MNH}_{2}^{+} \cdots \mathrm{H}_{2} \mathrm{AsO}_{3}{ }^{2-}(6.141)
\end{aligned}
$$

$\mathrm{MNH}_{2}{ }^{+}+\mathrm{H}_{2} \mathrm{AsO}_{4}{ }^{2-} \rightarrow \mathrm{MNH}_{2}^{+\cdots} \mathrm{H}_{2} \mathrm{AsO}_{4}{ }^{2-}$ (6.142)

(ii) electrostatic attraction between positively charged surface, hydroxyl group and $\mathrm{H}_{2} \mathrm{AsO}_{3}{ }^{-}$and $\mathrm{H}_{2} \mathrm{AsO}_{4}{ }^{-}(\mathrm{Hu}$ et al. 2005):

$\mathrm{MOH}_{2}{ }^{+}+\mathrm{H}_{2} \mathrm{AsO}_{3}{ }^{-} \rightarrow \mathrm{MOH}_{2}^{+\cdots-}{ }^{-} \mathrm{O}_{3} \mathrm{AsH}_{2} \quad$ (electrostatic attraction) (6.143)

$\mathrm{MOH}_{2}{ }^{+}+\mathrm{H}_{2} \mathrm{AsO}_{4}{ }^{-} \rightarrow \mathrm{MOH}_{2}^{+\cdots \cdots-} \mathrm{O}_{4} \mathrm{AsH}_{2} \quad$ (electrostatic attraction) (6.144)

and (iii) ion exchange reaction between positively charged metal centre and $\mathrm{H}_{2} \mathrm{AsO}_{3}{ }^{-}$and $\mathrm{H}_{2} \mathrm{AsO}_{4}{ }^{-}$:

$\mathrm{MOH}_{2}{ }^{+}+\mathrm{H}_{2} \mathrm{AsO}_{3}{ }^{-} \rightarrow \mathrm{M} . . . \mathrm{OAsO}_{3} \mathrm{H}_{2}+2 \mathrm{H}_{2} \mathrm{O}$ (ion exchange) (6.145)

$\mathrm{MOH}_{2}{ }^{+}+\mathrm{H}_{2} \mathrm{AsO}_{4}{ }^{-} \rightarrow \mathrm{M} . . . \mathrm{OAsO}_{3} \mathrm{H}_{2}+2 \mathrm{H}_{2} \mathrm{O}$ (ion exchange) (6.146)

b) Again while the $\mathrm{pH}$ of the solution remains moderately in a neutral range $(\mathrm{pH} 7.0)$, phycoremediation of $\mathrm{As}(\mathrm{III})$ or $\mathrm{As}(\mathrm{V})$ on the neutral microalgal biomass surface can be defined by a ligand or ion exchange reaction mechanism, which is characterized as follows (Mandal et al. 2011; Giri et al. 2013):

$\mathrm{MOH}+\mathrm{AsO}_{3}{ }^{3-} \rightarrow \mathrm{M}^{+\ldots} \mathrm{AsO}_{3}{ }^{3-}+\mathrm{OH}^{-}$(ligand or ion exchange) (6.147)

$\mathrm{MOH}+\mathrm{H}_{2} \mathrm{AsO}_{3}{ }^{-} \rightarrow \mathrm{M}-\mathrm{OAsO}_{3} \mathrm{H}_{2}+\mathrm{OH}^{-}$(ligand or ion exchange) (6.148)

$\mathrm{MOH}+\mathrm{AsO}_{4}{ }^{3-} \rightarrow \mathrm{M}^{+\ldots} \mathrm{AsO}_{4}{ }^{3-}+\mathrm{OH}^{-}$(ligand or ion exchange) (6.149)

$\mathrm{MOH}+\mathrm{H}_{2} \mathrm{AsO}_{4}{ }^{-} \rightarrow \mathrm{M}-\mathrm{OAsO}_{4} \mathrm{H}_{2}+\mathrm{OH}^{-}$(ligand or ion exchange) (6.150)

c) At $\mathrm{pH}$ above $>7.0$, the surface is hydroxylated and expressed as $\mathrm{MO}^{-}$and the negatively charged surface can exchange $\mathrm{AsO}_{3}{ }^{3-}$ or $\mathrm{H}_{2} \mathrm{AsO}_{3}{ }^{-}$and $\mathrm{AsO}_{4}{ }^{3-}$ or $\mathrm{H}_{2} \mathrm{AsO}_{4}{ }^{-}$ anions as follows ( $\mathrm{Hu}$ et al. 2005):

$$
\mathrm{MO}^{-}+\mathrm{AsO}_{3}{ }^{-}+\mathrm{H}_{2} \mathrm{O} \rightarrow \mathrm{MOH}-\mathrm{AsO}_{3}{ }^{3-}+\mathrm{OH}^{-}
$$

(6.151)

$$
\begin{aligned}
& \mathrm{MO}^{-}+\mathrm{H}_{2} \mathrm{AsO}_{3}{ }^{-}+\mathrm{H}_{2} \mathrm{O} \rightarrow \mathrm{MOH}-\mathrm{AsO}_{3}{ }^{3-}+\mathrm{OH}^{-} \\
& \mathrm{MO}^{-}+\mathrm{AsO}_{4}{ }^{-}+\mathrm{H}_{2} \mathrm{O} \rightarrow \mathrm{MOH}-\mathrm{AsO}_{4}{ }^{3-}+\mathrm{OH}^{-} \\
& \mathrm{MO}^{-}+\mathrm{H}_{2} \mathrm{AsO}_{4}{ }^{-}+\mathrm{H}_{2} \mathrm{O} \rightarrow \mathrm{MOH}-\mathrm{AsO}_{4}{ }^{3-}+\mathrm{OH}^{-}
\end{aligned}
$$

(6.154)

The modelling of the exact phycoremediation of $\mathrm{AsO}_{3}{ }^{3-}$ or $\mathrm{H}_{2} \mathrm{AsO}_{3}{ }^{-}$and $\mathrm{AsO}_{4}{ }^{3-}$ or $\mathrm{H}_{2} \mathrm{AsO}_{4}{ }^{-}$on any material surface is dependent on a number of peripheral parameters such as $\mathrm{pH}$, temperature, initial concentration of arsenic (either As(III) or As(V)) and the density of surface functional groups existing for coordination.

\section{Effect of inoculum size on phycoremediation properties of $C$. pyrenoidosa}

The impact of inoculum size on phycoremediation of $C$. pyrenoidosa was carried out by varying inoculum volume in the range of $2-20 \%(\mathrm{v} / \mathrm{v})$ in the growth media containing 
$50 \mathrm{mg} / \mathrm{L}$ of arsenic (either $\mathrm{As}(\mathrm{III})$ or $\mathrm{As}(\mathrm{V})$ ), at an initial optimized $\mathrm{pH}$ value of 9.0 , contact time $144 \mathrm{~h}$ and temperature $28{ }^{\circ} \mathrm{C}$.

For the two arsenic species (As(III) and As(V)), virtually no change was observed in the phycoremediation $\%$ for the inoculum size in the range of $2-8 \%(\mathrm{v} / \mathrm{v})$ and then scavenging enhanced sharply and reached the highest at inoculum size of $10 \%(\mathrm{v} / \mathrm{v})$. Then a sharp drop in the phycoremediation $\%$ was found (Fig. 2a, b).

With the increase in inoculum size the biomass concentration increases, reaches a maximum and then it declines with the increase of inoculum size. In the present study, biomass concentration increased when the inoculum size was increased from 1 to $10 \%(\mathrm{v} / \mathrm{v})$ and then it started to decrease. For $1 \%(\mathrm{v} / \mathrm{v})$ inoculum, the As(III) and $\mathrm{As}(\mathrm{V})$ phycoremediation \% was 62.609 and 68.154 , which

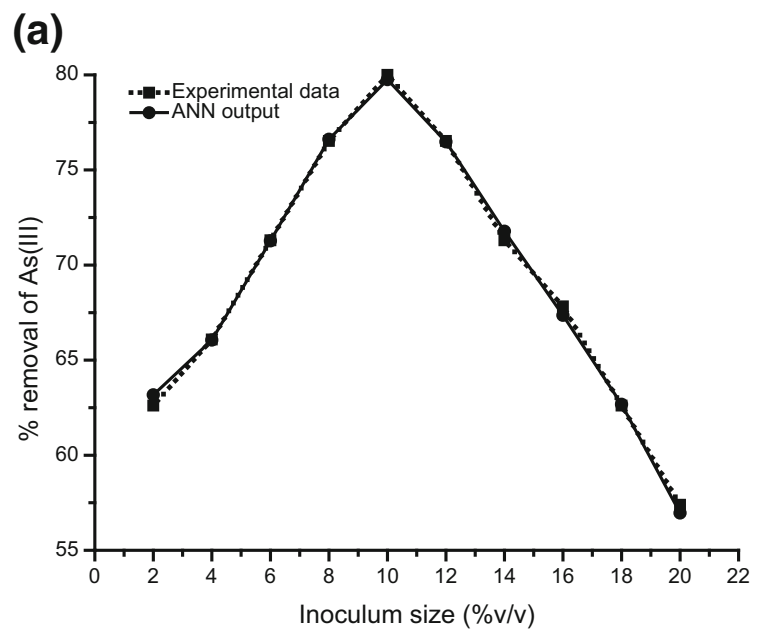

(b)

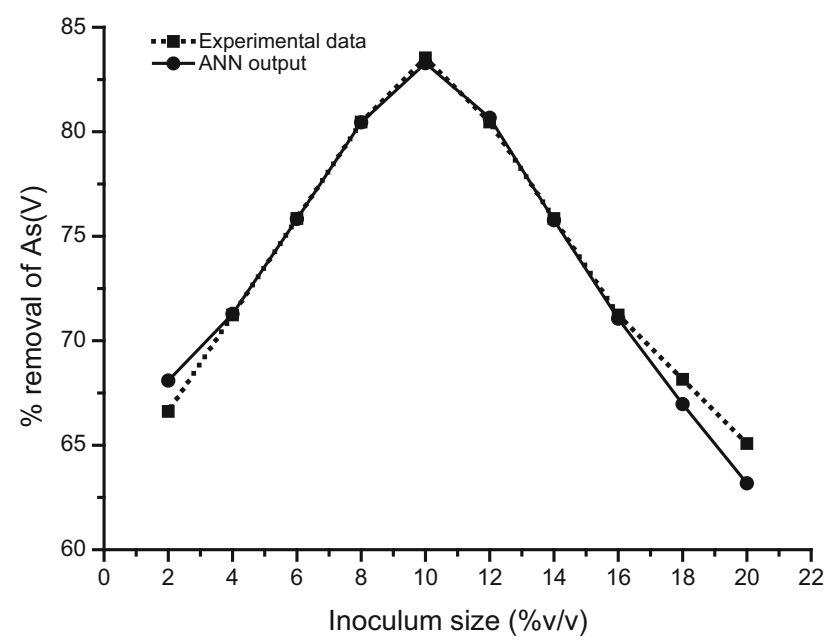

Fig. 2 Experimental data and ANN outputs as a function of inoculum size versus (\%) removal of a $\mathrm{As}(\mathrm{III})$ and $\mathbf{b} \mathrm{As}(\mathrm{V})$ by Chlorella pyrenoidosa (experimental conditions: initial $\mathrm{pH}$ : 9.0; contact time: $144 \mathrm{~h}$; initial arsenic concentration: $50 \mathrm{mg} / \mathrm{L}$; temperature: $28^{\circ} \mathrm{C}$ ) increased to 80 and 83.538 , respectively, at $10 \%(\mathrm{v} / \mathrm{v})$ inoculum of $C$. pyrenoidosa algae and then decreased to 60.87 and 77.38 , respectively, at an inoculum size of $20 \%$ $(\mathrm{v} / \mathrm{v})$. It was supported by the change in biomass concentration.

At inoculum volume $<10 \%$ (v/v), an improved distribution $\mathrm{CO}_{2}$ as well as more efficient nutrient uptake also leads to a higher growth of algae when inoculum size was low, although optical density of cell suspension was found to be low. This may be due to the overpopulated culture and fixed amount of nutrient with which the microorganisms begin to liberate proteolytic enzyme enhancing selfconsumption (Srinath et al. 2002; Jayanthi et al. 2013). So fixed amount of inoculums were optimized and $10 \%(\mathrm{v} / \mathrm{v})$ of inoculum volume gave the best result than other size of inoculum. On the other hand, higher inoculum sizes [ $>10 \%$ $(\mathrm{v} / \mathrm{v})$ ] could result in the lack of carbon dioxide and depletion of nutrient in the culture media. So the maximum phycoremediation of arsenic [either As(III) or As(V)] was found using $10 \%$ inoculum size.

The results acquired from experimental studies are presented into the ANN model and predicted with sensible exactness, which supports the drift of experimental outcomes (Fig. 2a, b).

\section{Effect of contact time on phycoremediation properties of $C$. pyrenoidosa}

The effect of contact time on the removal of both As(III) and $\operatorname{As}(\mathrm{V})$ was examined by culturing $C$. pyrenoidosa in $100 \mathrm{~mL}$ of synthetic wastewater containing $50 \mathrm{mg} / \mathrm{L}$ of arsenic (either $\mathrm{As}(\mathrm{III})$ or $\mathrm{As}(\mathrm{V})$ ) and keeping inoculum size and $\mathrm{pH}$ constant at $10 \%$ and 9.0 , respectively. The study reveals the high potential of $C$. pyrenoidosa in the removal of both $\mathrm{As}(\mathrm{III})$ and $\mathrm{As}(\mathrm{V})$ from synthetic wastewater. Figure $3 \mathrm{a}, \mathrm{b}$ represent the variation of $\%$ removal of both $\mathrm{As}(\mathrm{III})$ and $\mathrm{As}(\mathrm{V})$ with time. An S-shaped growth curve was found with both $\mathrm{As}(\mathrm{III})$ and $\mathrm{As}(\mathrm{V})$. This characterizes the effective growth of $C$. pyrenoidosa biomass in synthetic wastewater. From Fig. 3a, b, it is clear that the \% removal of $\mathrm{As}(\mathrm{V})$ is higher than that of $\mathrm{As}(\mathrm{III})$. After $168 \mathrm{~h}$ of growth, the \% removal of both $\mathrm{As}(\mathrm{III})$ and $\mathrm{As}(\mathrm{V})$ was found to increase from 38.261 to 81.739 and 40.462 to 85.077 , respectively, when contact time varies from 4 to $168 \mathrm{~h}$. Time to achieve equilibrium was $168 \mathrm{~h}$ for both As(III) and As(V).

From the consequences it is clear that in all the systems, the saturation time does not be ruled by the adsorbate concentration in the solution. The change in the rate of removal might be due to the fact that originally all sites of algal biomass surfaces are easily available and furthermore the concentration gradient of adsorbate is very high. At optimum $\mathrm{pH}$, the fast kinetics of interaction of adsorbate- 
(a)

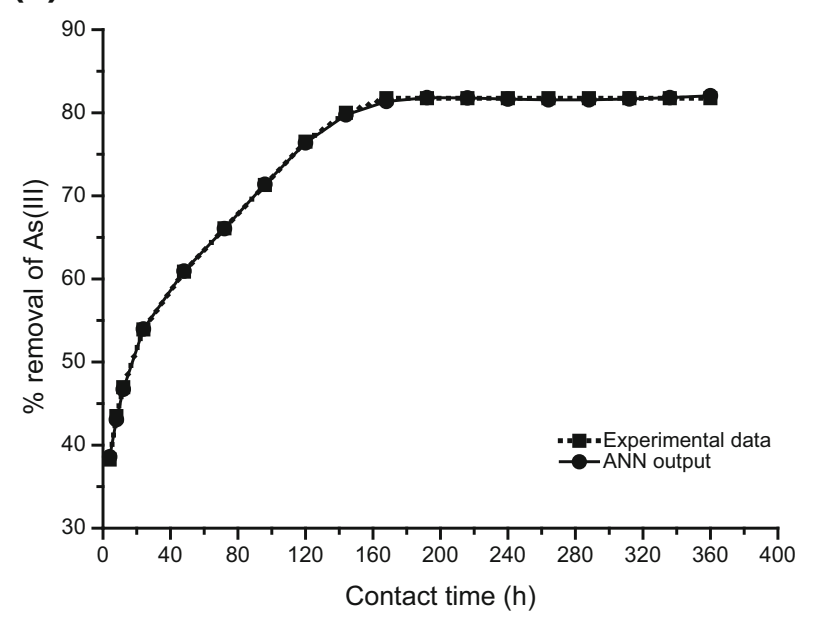

(b)

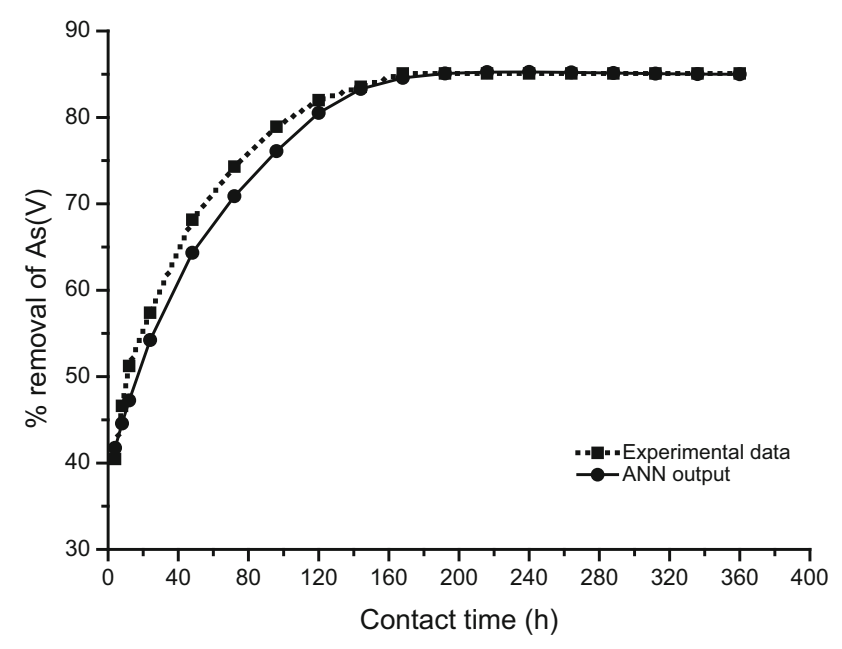

Fig. 3 Experimental data and ANN outputs as a function of contact time versus (\%) removal of a $\mathrm{As}(\mathrm{III})$ and $\mathbf{b} \mathrm{As}(\mathrm{V})$ by Chlorella pyrenoidosa (experimental conditions: initial $\mathrm{pH}$ : 9.0; inoculum size $(\% \mathrm{v} / \mathrm{v}): 10$; initial arsenic concentration: $50 \mathrm{mg} / \mathrm{L}$; temperature: $\left.28{ }^{\circ} \mathrm{C}\right)$

algal biomass might be clear to increase availability of the active sites of the algal biomass surface. So the removal of adsorbate was fast in the early stages and gradually decreases with the interval of time until equilibrium in each case. The decrease in removal of metal ions at the later stage of the process was owing to the falling of concentration of metal ions (Mishra et al. 2010).

The results of the effect of contact time on $\%$ removal specifies that the respective algae had an optimum residence time for $\mathrm{As}(\mathrm{III})$ and $\mathrm{As}(\mathrm{V})$ and when this time passed, phycoremediation continued either constant or diminished slightly. The constant nature of the \% removal curve after $168 \mathrm{~h}$ for both $\mathrm{As}(\mathrm{III})$ and $\mathrm{As}(\mathrm{V})$ may also be because of initiation of the stationary phase of the $C$. pyrenoidosa. (a)

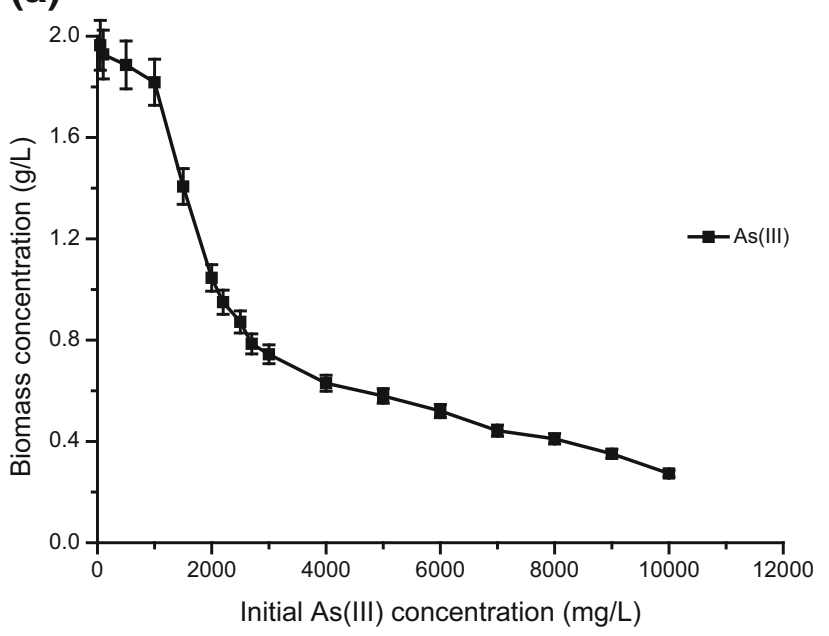

(b)

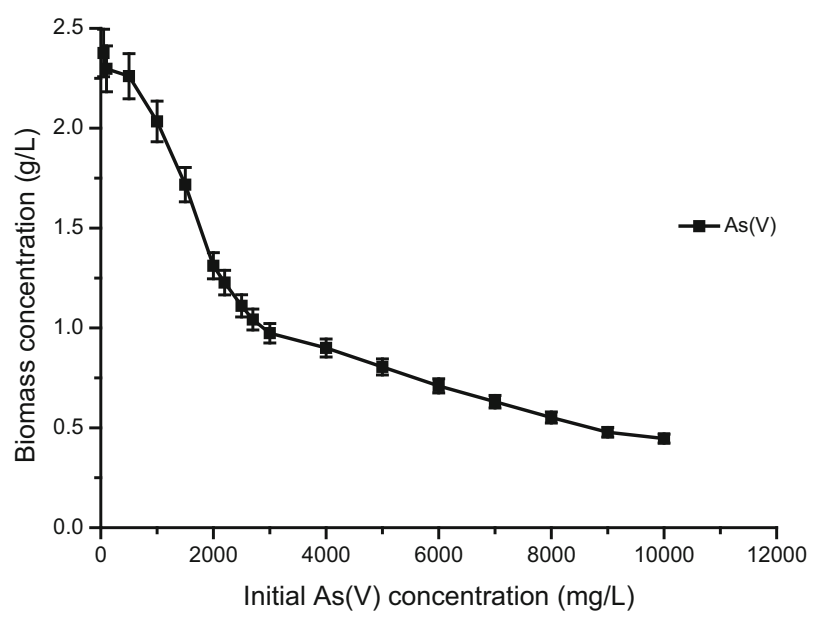

Fig. 4 Maximum tolerance of As(III) resistant and As(V) resistant $C$. glutamicum MTCC 2745 at different levels of initial concentration of a $\mathrm{As}(\mathrm{III})$ and b $\mathrm{As}(\mathrm{V})\left(\mathrm{pH}: 7.0\right.$; Inoculum size: $5 \%(\mathrm{v} / \mathrm{v})$; T: $30^{\circ} \mathrm{C}$; Agitation speed: $120 \mathrm{rpm}$; Incubation time: $24 \mathrm{~h}$ ) (Error bars represent means \pm standard errors from the mean of duplicate experiments)

The experimental results and ANN estimated results as a function of contact time for removal of As(III) and As(V) are shown in Fig. 3a, b. It can be observed that the ANN model exhibited a good performance on prediction of the experimental output.

\section{Maximum tolerance of microalgae}

Experiments were carried out in batch reactor to investigate the maximum tolerable concentration of arsenic (either As(III) or As(V)). Various initial arsenic (either As(III) or As $(\mathrm{V})$ ) concentration considered in the present study are 50, 100, 500, 1000, 1500, 2000, 2200, 2500, $2700 \mathrm{mg} / \mathrm{L}$, $3000,4000,5000,6000,7000,8000,9000$, and $10000 \mathrm{mg} /$ 
L. From Fig. $4 a, b$ the observations are made that the growth of microalgae decreased with the increase in arsenic (either $\mathrm{As}(\mathrm{III})$ or $\mathrm{As}(\mathrm{V})$ ) concentration from 50 to $10000 \mathrm{mg} / \mathrm{L}$, respectively. It can be explained by the fact that metal ion concentration plays a major role for the growth properties of microalgae $C$. pyrenoidosa. The Maximum Tolerable Concentration (MTC) of metal ion was selected as the highest concentration of metal ion that allows growth after 7 days. The increasing concentration of arsenic (either As(III) or As(V)) $(50,100,500,1000,1500$, 2000, 2200, 2500, 2700, 3000, 4000, 5000, 6000, 7000, 8000,9000 , and $10000 \mathrm{mg} / \mathrm{L}$ ) in the growth media were used for testing the MTCs. Growth of microalgae is highly sensitive to arsenic concentration. The absorbance (OD at $680 \mathrm{~nm}$ ) and biomass concentration of microalgae $C$. pyrenoidosa decreased from 0.484 and $2.34 \mathrm{~g} / \mathrm{L}$ to 0.114 and $0.388 \mathrm{~g} / \mathrm{L}$, respectively, with the increase of As(III) concentration from 50 to $10000 \mathrm{mg} / \mathrm{L}$. Similarly, the absorbance (OD at $680 \mathrm{~nm}$ ) and biomass concentration of microalgae $C$. pyrenoidosa decreased from 0.491 and 2.377 to 0.131 and $0.478 \mathrm{~g} / \mathrm{L}$, respectively, with the increase of $\mathrm{As}(\mathrm{V})$ concentration from 50 to $10000 \mathrm{mg} / \mathrm{L}$.

Table 4 Comparison of $\mathrm{As}(\mathrm{III})$ and $\mathrm{As}(\mathrm{V})$ phycoremdiation, at different levels of As(III) and As(V) concentration

\begin{tabular}{|c|c|c|c|}
\hline $\begin{array}{l}\text { Arsenic } \\
\text { species }\end{array}$ & $\begin{array}{l}\mathrm{C}_{0} \\
(\mathrm{mg} / \mathrm{L})\end{array}$ & $\begin{array}{l}\text { Phycoremediation } \\
(\%)\end{array}$ & $\begin{array}{l}\text { Arsenic conc. } \\
(\mathrm{mg} / \mathrm{L})\end{array}$ \\
\hline \multirow[t]{11}{*}{$\mathrm{As}(\mathrm{III})$} & 0 & - & - \\
\hline & 50 & 62.609 & 31.304 \\
\hline & 100 & 66.087 & 66.087 \\
\hline & 200 & 71.304 & 142.609 \\
\hline & 500 & 76.522 & 382.609 \\
\hline & 800 & 80 & 640 \\
\hline & 1000 & 76.522 & 765.217 \\
\hline & 1200 & 71.304 & 855.652 \\
\hline & 1500 & 67.827 & 1017.391 \\
\hline & 1800 & 62.609 & 1126.957 \\
\hline & 2000 & 57.391 & 1147.826 \\
\hline \multirow[t]{11}{*}{$\mathrm{As}(\mathrm{V})$} & 0 & - & - \\
\hline & 50 & 85.077 & 42.538 \\
\hline & 100 & 83.038 & 83.038 \\
\hline & 200 & 81 & 162 \\
\hline & 500 & 77.362 & 386.808 \\
\hline & 800 & 76.519 & 612.154 \\
\hline & 1000 & 72.7 & 727 \\
\hline & 1200 & 69.385 & 832.615 \\
\hline & 1500 & 66.044 & 990.654 \\
\hline & 1800 & 62.442 & 1123.962 \\
\hline & 2000 & 59.883 & 1197.654 \\
\hline
\end{tabular}

\section{Effect of initial As(III) and As(V) concentration on phycoremediation of $C$. pyrenoidosa}

The influence of initial metal ion concentration on phycoremediation using $C$. pyrenoidosa was performed by changing arsenic (either $\mathrm{As}(\mathrm{III})$ or $\mathrm{As}(\mathrm{V})$ ) concentrations $(50,100,200,500,800,1000,1200,1500,1800$ and $2000 \mathrm{mg} / \mathrm{L}$ ) in the growth media, at an initial optimized $\mathrm{pH}$ value of 9.0. The phycoremediation $\%$ and phycoremediation level of the As(III) and As(V) by the algal species at different initial arsenic (either As(III) or As(V)) concentrations were determined as presented in Table 4. For all the two arsenic species (As(III) and As(V)), phycoremediation \% in $C$. pyrenoidosa biomass reduced as the arsenic species concentration increased from 50 to $2000 \mathrm{mg} / \mathrm{L}$ are exposed in Fig. 5a, b.

(a)

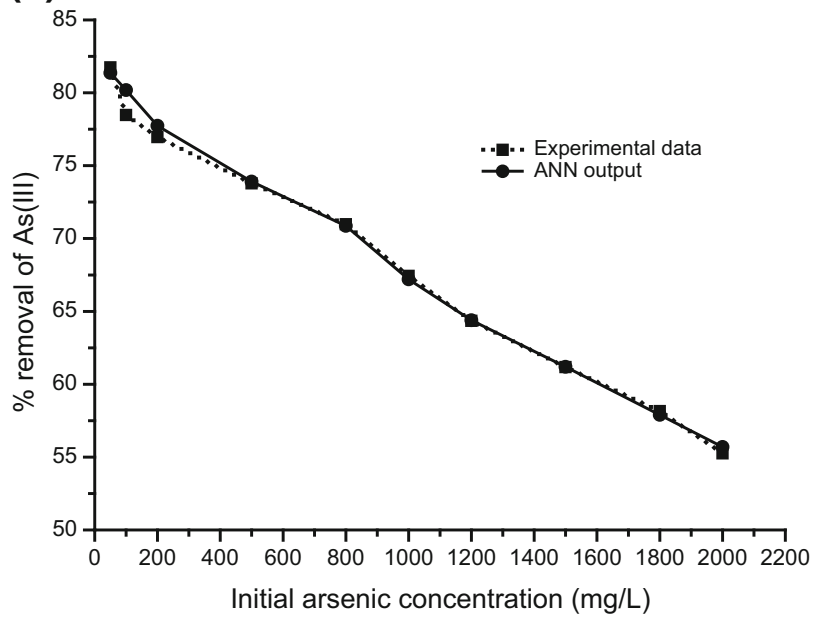

(b)

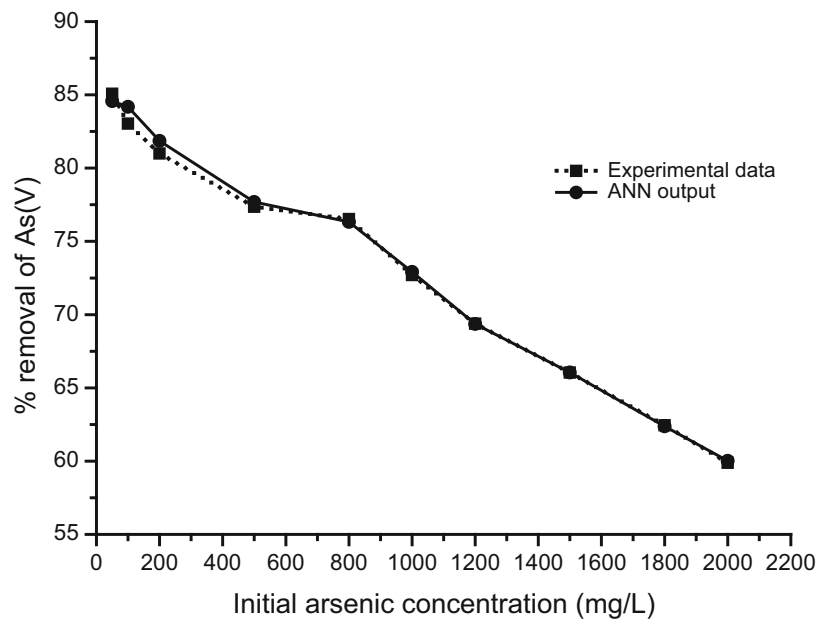

Fig. 5 Experimental data and ANN outputs as a function of initial arsenic concentration versus (\%) removal of $\mathbf{a} \mathrm{As}(\mathrm{III})$ and $\mathbf{b} \mathrm{As}(\mathrm{V})$ by Chlorella pyrenoidosa (experimental conditions: initial $\mathrm{pH}$ : 9.0; inoculum size (\% v/v): 10 ; contact time: $168 \mathrm{~h}$; temperature: $28{ }^{\circ} \mathrm{C}$ ) 


\section{(a)}

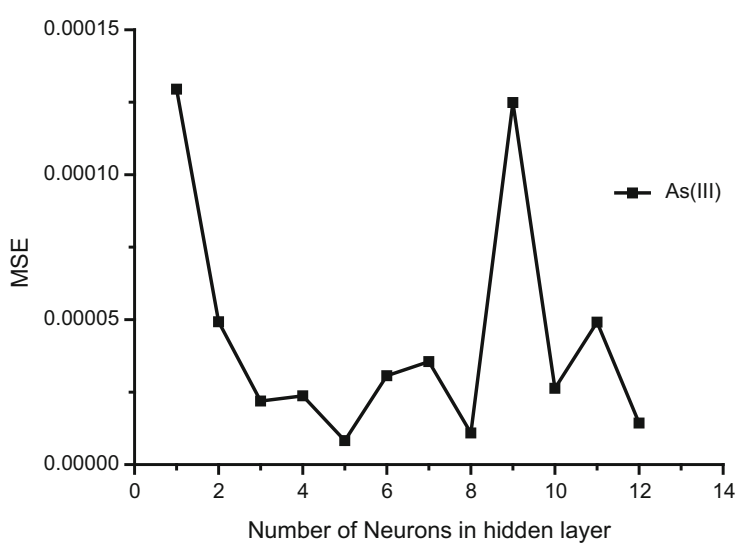

(b)

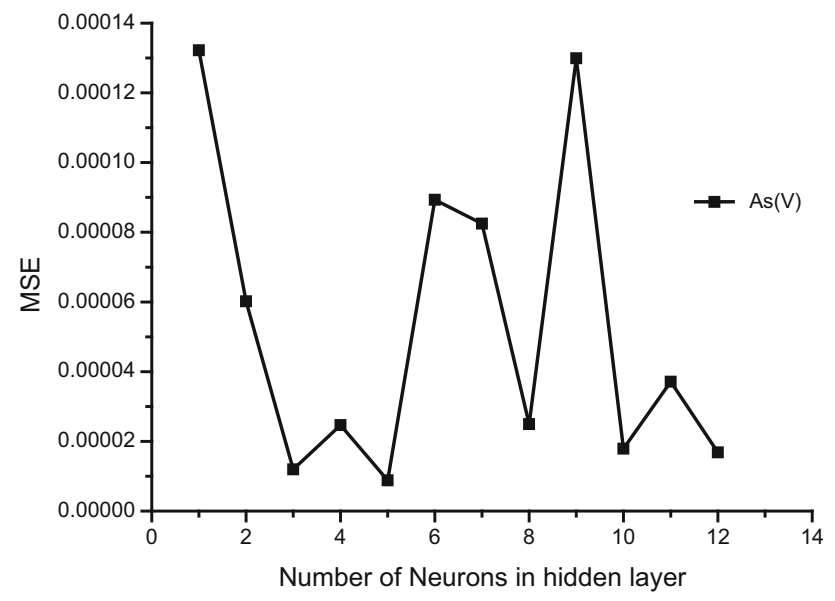

Fig. 6 Dependence between MSE and number of neurons at hidden layer Chlorella pyrenoidosa for a $\mathrm{As}(\mathrm{III})$ and $\mathbf{b} \mathrm{As}(\mathrm{V})$

With the increase of concentration of contaminants toxicity level increases, as a result biomass concentration decreases. In the present study, the biomass concentration reduced when the amount of phycoremediated arsenic [either $\mathrm{As}(\mathrm{III})$ or $\mathrm{As}(\mathrm{V})]$ species was increased from 50 to $2000 \mathrm{mg} / \mathrm{L}$. In the presence of $50 \mathrm{mg} / \mathrm{L}$ of $\mathrm{As}(\mathrm{III})$ and $\mathrm{As}(\mathrm{V})$, the phycoremediation \% was 81.739 and 85.077 , respectively, which was reduced to 55.25 and 59.883 at $2000 \mathrm{mg} / \mathrm{L}$ of $\mathrm{As}(\mathrm{III})$ and $\mathrm{As}(\mathrm{V})$, respectively. The reduction in phycoremediation $\%$ was also due to the toxicity of arsenic at higher concentrations which reduced the biomass concentration. Varying the concentration from 50 to $2000 \mathrm{mg} / \mathrm{L}$ resulted in increased phycoremediation levels from 31.304 to 1147.826 and 42.538 to $1197.654 \mathrm{mg} / \mathrm{L}$ for $\mathrm{As}(\mathrm{III})$ and As $(\mathrm{V})$, respectively.

In response to $\mathrm{As}(\mathrm{III})$ and $\mathrm{As}(\mathrm{V})$ the alga created phytochelatins $\left(\mathrm{PC}_{2-3}\right)$, but at $\mathrm{As}(\mathrm{V})$ exposure, their levels in cells were more than with As(III), suggesting greater
Table 5 Comparison of 12 neurons in the hidden layer for phycoremediation efficiency by ANN model development with the Levenberg-Marquardt algorithm using Chlorella pyrenoidosa

\begin{tabular}{lllll}
\hline As(III) species & & & As(V) species \\
\cline { 1 - 1 } \cline { 5 - 5 } Number of neurons & MSE & & Number of neurons & MSE \\
\hline 1 & $1.295 \mathrm{E}-04$ & 1 & $1.322 \mathrm{E}-04$ \\
2 & $4.924 \mathrm{E}-05$ & 2 & $6.018 \mathrm{E}-05$ \\
3 & $2.191 \mathrm{E}-05$ & 3 & $1.196 \mathrm{E}-05$ \\
4 & $2.371 \mathrm{E}-05$ & 4 & $2.466 \mathrm{E}-05$ \\
5 & $8.268 \mathrm{E}-06$ & 5 & $8.815 \mathrm{E}-06$ \\
6 & $3.064 \mathrm{E}-05$ & 6 & $8.932 \mathrm{E}-05$ \\
7 & $3.55 \mathrm{E}-05$ & 7 & $8.247 \mathrm{E}-05$ \\
8 & $1.088 \mathrm{E}-05$ & 8 & $2.494 \mathrm{E}-05$ \\
9 & $1.249 \mathrm{E}-05$ & 9 & $1.299 \mathrm{E}-04$ \\
10 & $2.63 \mathrm{E}-05$ & 10 & $1.792 \mathrm{E}-05$ \\
11 & $4.91 \mathrm{E}-05$ & 11 & $3.713 \mathrm{E}-05$ \\
12 & $1.43 \mathrm{E}-05$ & 12 & $1.684 \mathrm{E}-05$ \\
\hline
\end{tabular}

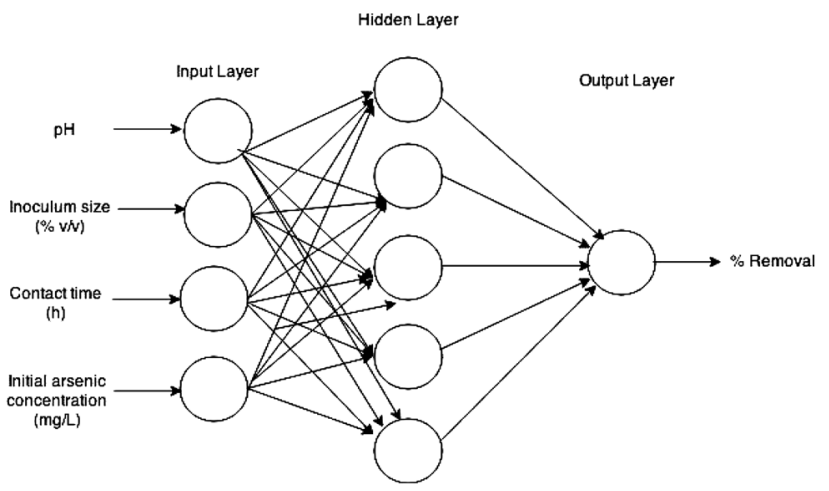

Fig. 7 The artificial neural network optimized structure

As(V) than As(III) accessibility and uptake. So the removal of $\mathrm{As}(\mathrm{V})$ is higher than $\mathrm{As}(\mathrm{III})$ for all concentrations (Pawlik-Skowrónska et al. 2004).

Figure 5a, b shows the comparison between experimental data as a function of initial arsenic concentration (As(III) and $\mathrm{As}(\mathrm{V}))$ and ANN model prediction. It can be noted that ANN model predicts suitably the drift of experimental data.

\section{Optimization of the ANN structure}

The optimization of network is very significant stage in network training. The relationship between the input and output data was attained by ANN to approximate any function with finite number of discontinuities by learning their relationships (Hagan et al. 1996). The network is tested with various numbers of neurons from 1 to 12 for finding the optimum number of neurons at hidden layer by finding the mean squared error (MSE). 
During training phase, the output vector is calculated by a forward pass in which the input is propagated forward through the network for computing the output value of each unit. Then the output vector is compared with the desired vector which resulted into error signal for each output unit. So as for minimizing the error, appropriate adjustments were made. After numerous such iterations, the network was trained for giving the desired output for a given input vector. The network was trained till minimum mean square error was acquired.

As it can be observed (Fig. 6a, b), the smallest MSE was taken into account for train function, when the consequence of Table 5 exhibits the relation between the number of neurons and MSE for existing ANN. According to Fig. 6a, $\mathrm{b}$, the optimum number of neurons at hidden layer is equal to 5 as the best case with the minimum value of MSE (8.268E-06 and 8.815E-06) for both As(III) and As(V). The hidden layers act like feature detectors. Consequently

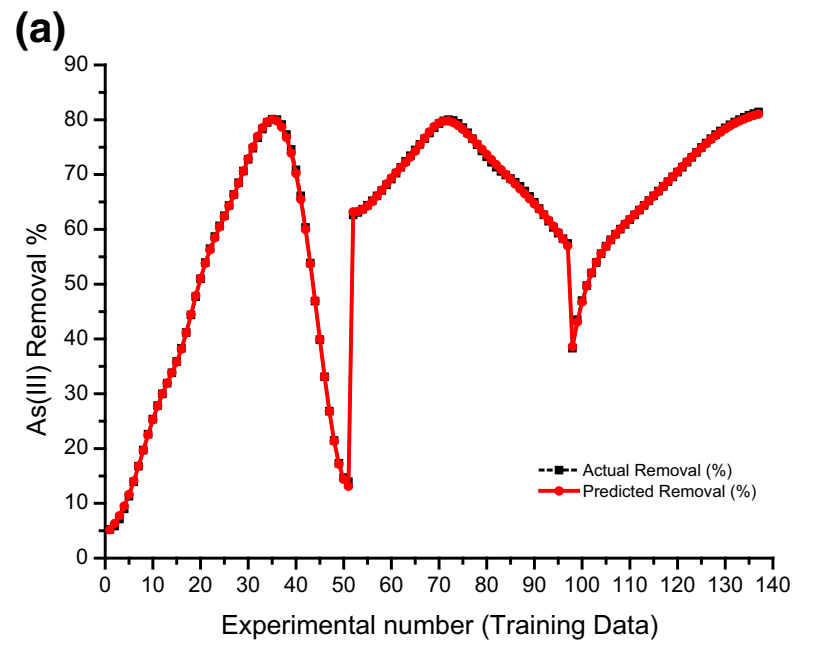

(b)

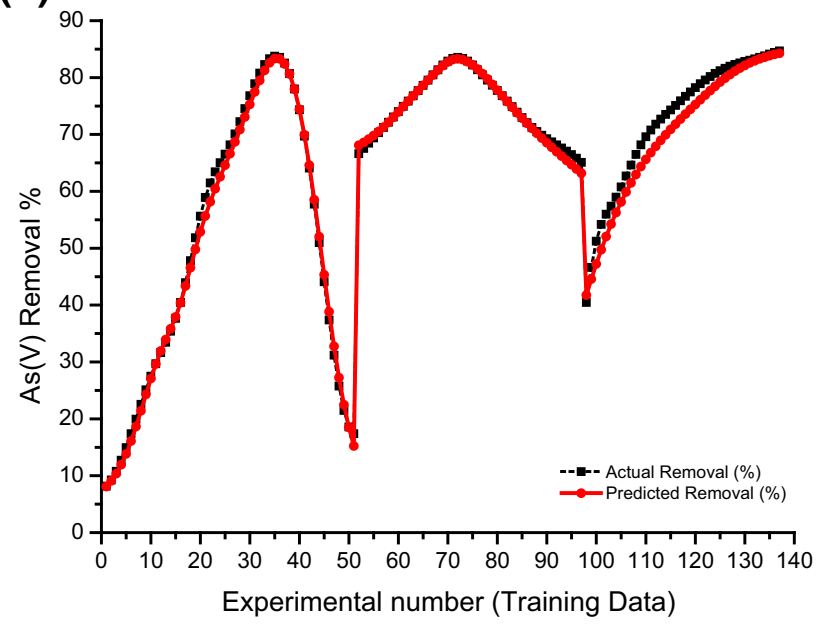

Fig. 8 Distribution of \% Removal a As(III) and b As(V) (training data) in this investigation three-layer feed-forward back propagation neural network $(4: 5: 1)$ was used to model the phycoremediation of both As(III) and As(V).

Fig. S2 of supplementary materials shows the proposed optimum ANN type for both As(III) and As(V). Hence, one of the optimum topology of ANN in the current investigation, as presented in Fig. 7, is parallel interconnected structure including: (1) input layer of neurons correspond to four independent experimental parameters (2) 5 neurons in the hidden layer, (3) and output layer corresponds \% removal for both $\mathrm{As}(\mathrm{III})$ and $\mathrm{As}(\mathrm{V})$. The hidden layer having 5 neurons used a tangent sigmoid activation function (tansig) and lastly the output layer having 1 neuron used a linear activation function (purelin).

If the number of neurons in the hidden layer is more, the network becomes complicated. Results possibly specify

(a)

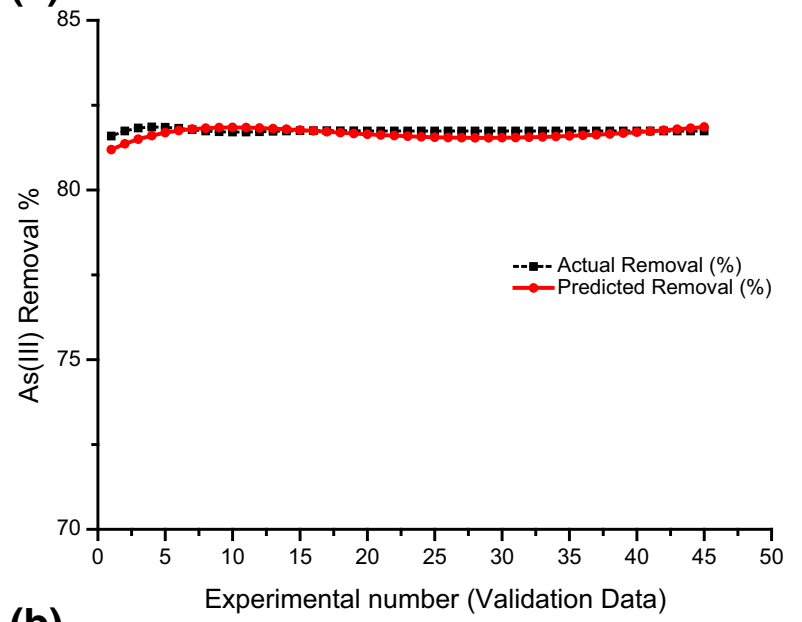

(b)

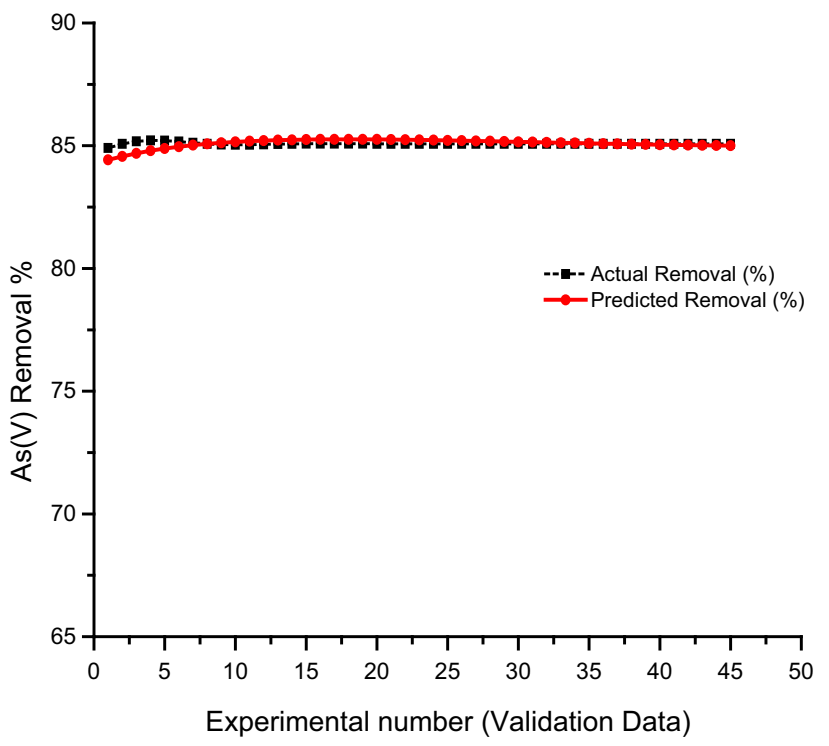

Fig. 9 Distribution of \% Removal a As(III) and b As(V) (validation data) 
that the present problem (predicting the \% removal of arsenic (either $\mathrm{As}(\mathrm{III})$ or $\mathrm{As}(\mathrm{V})$ ) using the algae $C$. pyrenoidosa) is not so complex as to require a complicated network routing. Therefore, the outcomes were suitably attained by keeping the number of neurons in the hidden layer at one of the optimum number of five.

The performance of the network is governed by the weight (traingdm), net input and transfer (tansig) functions. A mean square error of 8.268E-06 and 8.815E-06 were observed at epoch number 72 and 53, respectively, for As(III) and As(V), respectively. Training was stopped at this point and weights have been frozen for network for undergoing testing phase. Fig. S3a, b of supplementary materials shows the MSE versus the number of epochs for optimal ANN models exhibit that the training was stopped after 73 and 53 for $\mathrm{As}(\mathrm{III})$ and $\mathrm{As}(\mathrm{V})$, respectively. Fig. S3a, b of supplementary materials also shows the reduction of the MSE throughout the training process. Training stops while any of these following situations are

(a)

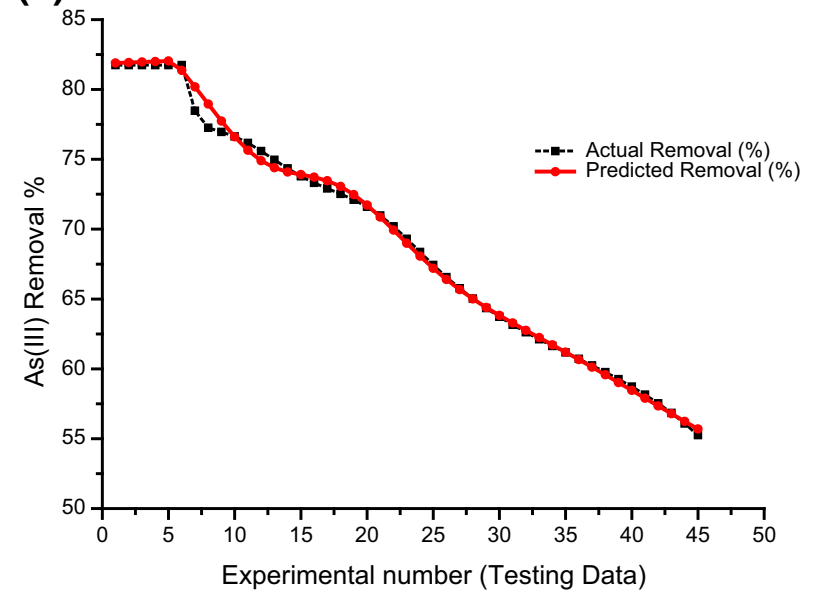

(b)

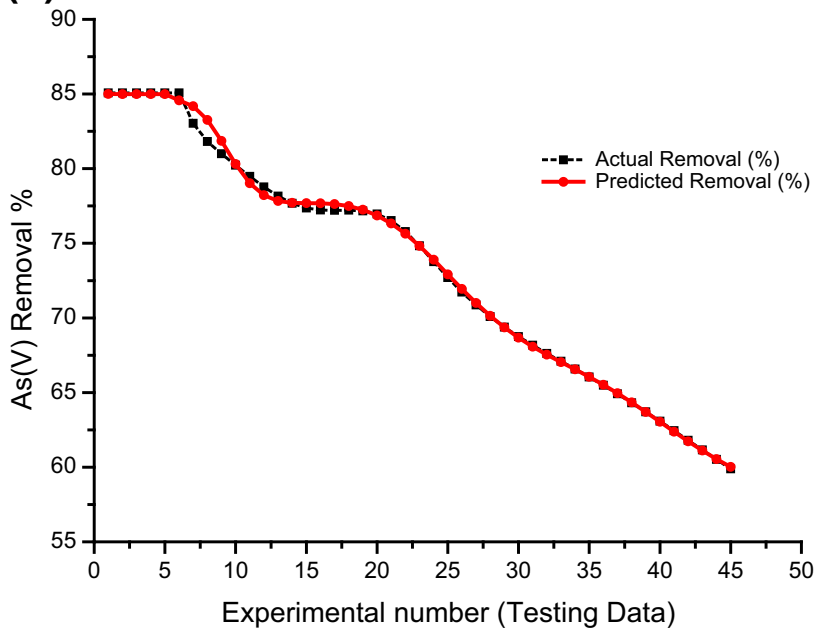

Fig. 10 Distribution of \% Removal a As(III) and b As(V) (testing data) happening: (1) The highest number of epochs is achieved; (2) The highest amount of training time is beaten; (3) Performance is minimized to the target and (4) Validation time beats higher than maximum fails.

The good simulation and correlation of experimental and predicted outcomes (train, validation, test and all data) of the \% removal of arsenic (either As(III) or As(V)) for the optimum number of hidden layer neurons are shown in Fig. S4a, b and Fig. S5a, b of supplementary materials, respectively, which approve the exactness of the neural network to model and predict the outlet composition of removal parameters. This ANN model specified an accurate and efficient prediction of the experimental data of As(III) with a correlation coefficient $\left(R^{2}\right)$ of 0.99984 , $0.99991,0.99991$ and 0.99987 for training, validation, testing and all data, respectively, and that of $\mathrm{As}(\mathrm{V})$ with a correlation coefficient $\left(\mathrm{R}^{2}\right)$ of $0.99984,0.99991,0.99992$ and 0.99987 for training, validation, testing and all data, respectively. The $R^{2}$ value acquired in this case is $>0.99$ which displays best fitting of model to data. Outcomes of

(a)

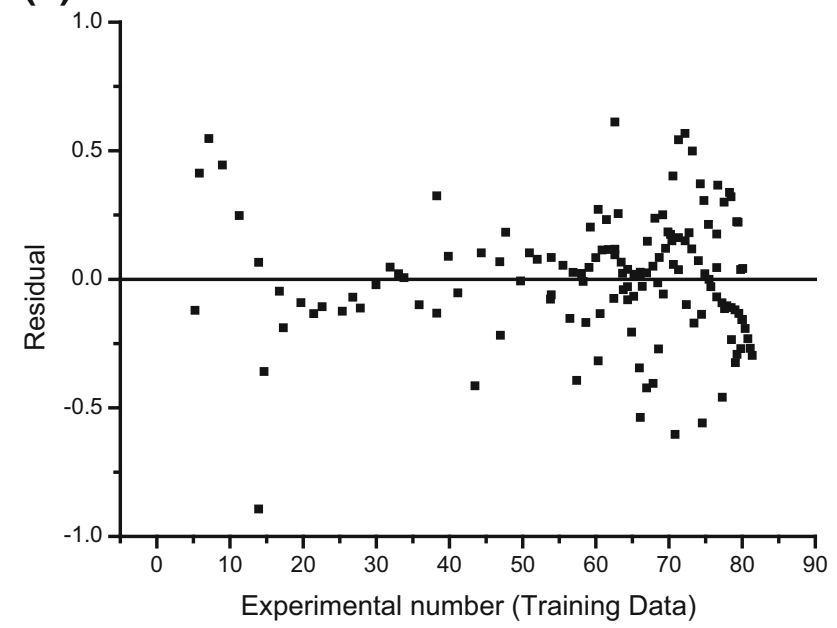

(b)

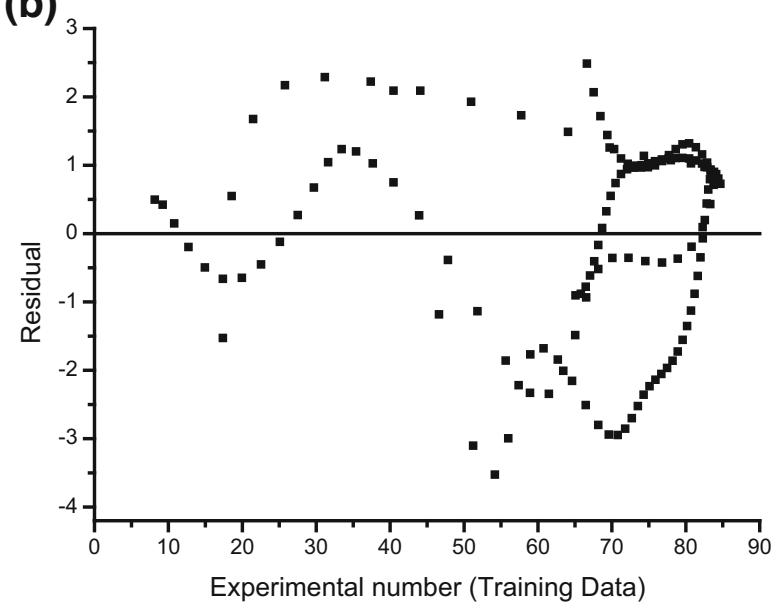

Fig. 11 Distribution of a $\mathrm{As}(\mathrm{III})$ and $\mathbf{b} \mathrm{As}(\mathrm{V})$ residual (training data)

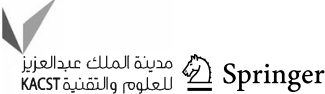


prediction by neural network $\left(\mathrm{R}^{2}\right)$ for training, validation and testing are given in Table 3 .

\section{Prediction of phycoremediation efficiency using ANN}

The distribution of output of training data is presented in Fig. 8a, b for As(III) and As(V), respectively. A high degree of correlation between actual and predicted removal efficiency (\%) were found as presented in Fig. S6a, b of supplementary materials for As(III) and As(V), respectively. Coefficient of determination $\left(R^{2}\right)$ of 0.99985 and 0.99505 are acquired for training data set of As(III) and As $(V)$, respectively. While the network was well trained, validation and testing of the network with the corresponding validation and testing data set were performed. The prediction capability of the developed network model for responses of experimental data is not forming part of the training data-set.

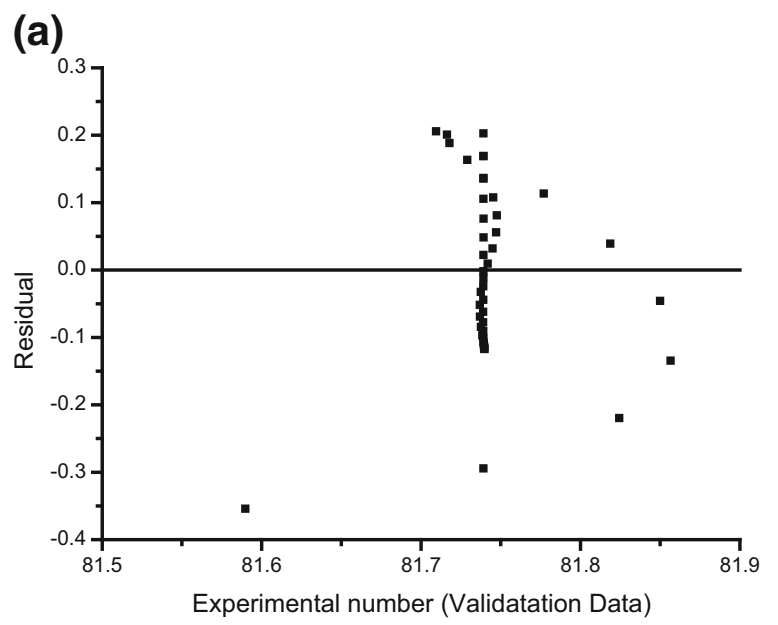

(b)

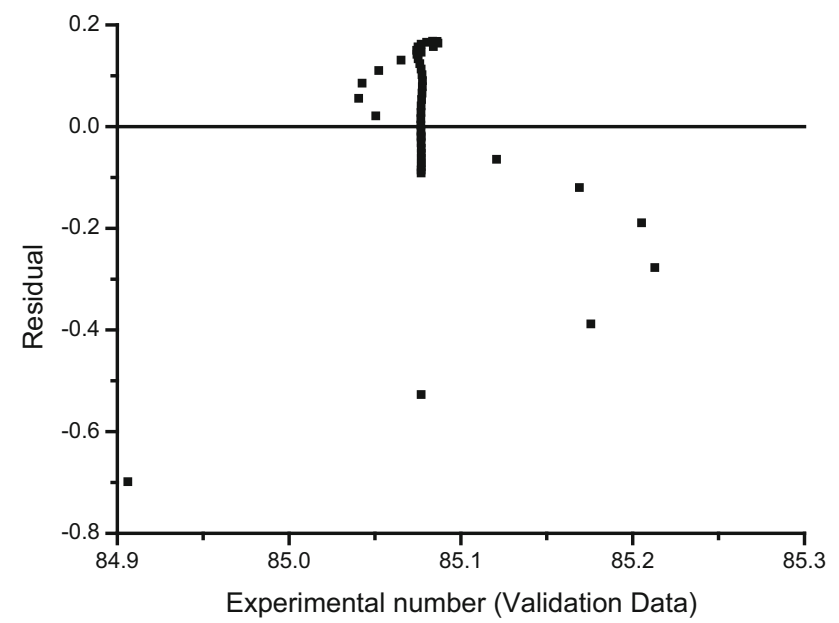

Fig. 12 Distribution of a $\mathrm{As}(\mathrm{III})$ and $\mathbf{b} \mathrm{As}(\mathrm{V})$ residual (validation data)
The distribution of output of validation data are exhibited in Fig. 9a, b for As(III) and As(V), respectively. The degree of correlation ( $\mathrm{R}^{2}$ equal to 0.04165 and 0.00159 ) between actual and predicted \% removal were found as shown in Fig. S7a, b of supplementary materials for validation data-set of $\mathrm{As}(\mathrm{III})$ and $\mathrm{As}(\mathrm{V})$, respectively.

The distribution of output of testing data is exposed in Fig. 10a, b for $\mathrm{As}(\mathrm{III})$ and $\mathrm{As}(\mathrm{V})$, respectively. A high degree of correlation ( $R^{2}$ equal to 0.99712 and 0.99899$)$ between actual and predicted \% removal were found as presented in Fig. S8a, b of supplementary materials for testing data-set of $\mathrm{As}(\mathrm{III})$ and $\mathrm{As}(\mathrm{V})$, respectively.

The residuals for training, validation and testing data of $\mathrm{As}(\mathrm{III})$ and $\mathrm{As}(\mathrm{V})$ were plotted in Figs. 11a, b, 12a, b and $13 \mathrm{a}, \mathrm{b}$, respectively. It can be found that the residuals were uniformly distributed above and below zero line. So it can be expected that the errors were distributed normally and

(a)

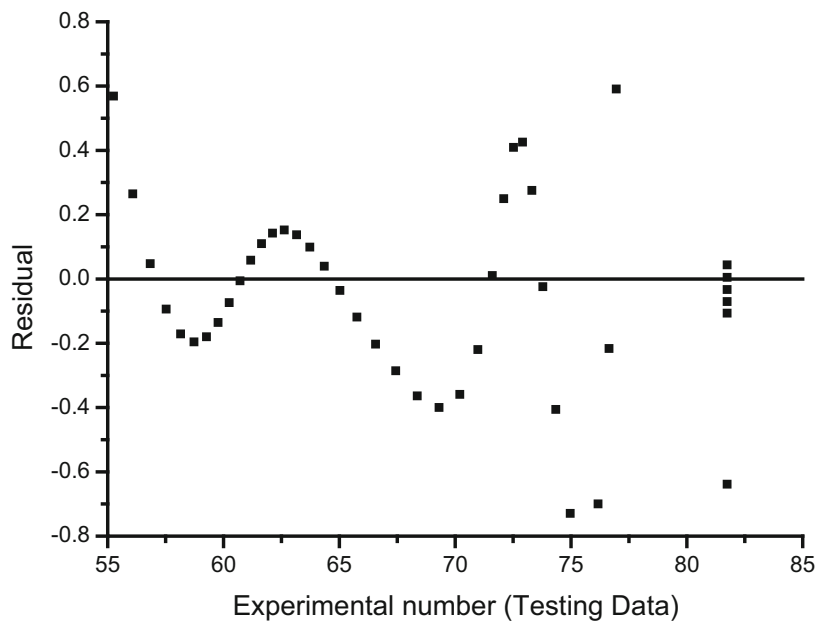

(b)

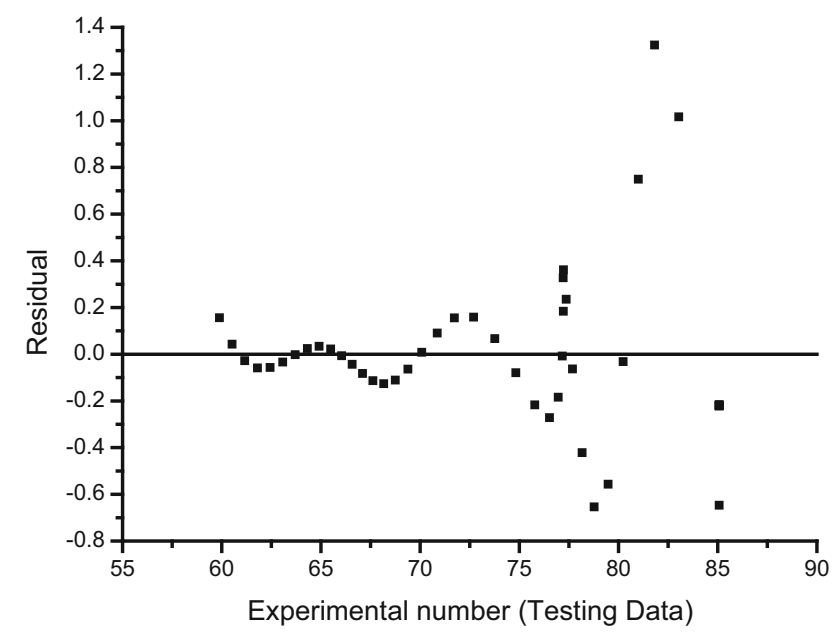

Fig. 13 Distribution of $\mathbf{a} \mathrm{As}(\mathrm{III})$ and $\mathbf{b} \mathrm{As}(\mathrm{V})$ residual (testing data) 
Table 6 Comparison of experimental and predicted As(III) removal efficiency on all data (Training, validation and testing)

\begin{tabular}{|c|c|c|c|c|c|c|c|c|c|c|}
\hline $\begin{array}{l}\text { Run } \\
\text { No. }\end{array}$ & $\mathrm{pH}$ & $\begin{array}{l}\text { Inoculum } \\
\text { size }\end{array}$ & $\begin{array}{l}\text { Contact } \\
\text { time (h) }\end{array}$ & $\begin{array}{l}\text { Initial arsenic } \\
\text { conc. }(\mathrm{mg} / \mathrm{L})\end{array}$ & $\begin{array}{l}\text { Actual } \\
\text { Removal (\%) }\end{array}$ & $\begin{array}{l}\text { Predicted } \\
\text { Removal }(\%)\end{array}$ & $\begin{array}{l}\text { Residual } \\
(\%)\end{array}$ & $\begin{array}{l}\text { Error } \\
(\%)\end{array}$ & $\begin{array}{l}\text { Absolute } \\
\text { error }\end{array}$ & $\begin{array}{l}\text { Standard } \\
\text { deviation (SD) }\end{array}$ \\
\hline 1 & 2 & 10 & 144 & 50 & 5.217 & 5.176 & 0.042 & 0.807 & 0.807 & 0.021 \\
\hline 2 & 3 & 10 & 144 & 50 & 13.913 & 14.038 & -0.125 & -0.890 & 0.890 & 0.062 \\
\hline 3 & 4 & 10 & 144 & 50 & 27.826 & 27.741 & 0.085 & 0.305 & 0.305 & 0.042 \\
\hline 4 & 5 & 10 & 144 & 50 & 38.261 & 38.133 & 0.128 & 0.336 & 0.336 & 0.064 \\
\hline 5 & 6 & 10 & 144 & 50 & 53.913 & 53.821 & 0.092 & 0.171 & 0.171 & 0.046 \\
\hline 6 & 7 & 10 & 144 & 50 & 64.348 & 64.264 & 0.084 & 0.131 & 0.131 & 0.042 \\
\hline 7 & 8 & 10 & 144 & 50 & 74.783 & 75.010 & -0.227 & -0.303 & 0.303 & 0.113 \\
\hline 8 & 9 & 10 & 144 & 50 & 80.000 & 79.752 & 0.248 & 0.311 & 0.311 & 0.124 \\
\hline 9 & 10 & 10 & 144 & 50 & 66.087 & 65.490 & 0.597 & 0.911 & 0.911 & 0.298 \\
\hline 10 & 11 & 10 & 144 & 50 & 33.043 & 33.080 & -0.037 & -0.111 & 0.111 & 0.018 \\
\hline 11 & 12 & 10 & 144 & 50 & 13.913 & 13.078 & 0.835 & 6.382 & 6.382 & 0.417 \\
\hline 12 & 9 & 2 & 144 & 50 & 62.609 & 63.169 & -0.560 & -0.887 & 0.887 & 0.280 \\
\hline 13 & 9 & 4 & 144 & 50 & 66.087 & 66.055 & 0.032 & 0.049 & 0.049 & 0.016 \\
\hline 14 & 9 & 6 & 144 & 50 & 71.304 & 71.270 & 0.034 & 0.048 & 0.048 & 0.017 \\
\hline 15 & 9 & 8 & 144 & 50 & 76.522 & 76.615 & -0.093 & -0.121 & 0.121 & 0.047 \\
\hline 16 & 9 & 10 & 144 & 50 & 80.000 & 79.752 & 0.248 & 0.311 & 0.311 & 0.124 \\
\hline 17 & 9 & 12 & 144 & 50 & 76.522 & 76.484 & 0.038 & 0.049 & 0.049 & 0.019 \\
\hline 18 & 9 & 14 & 144 & 50 & 71.304 & 71.776 & -0.471 & -0.657 & 0.657 & 0.236 \\
\hline 19 & 9 & 16 & 144 & 50 & 67.826 & 67.358 & 0.468 & 0.695 & 0.695 & 0.234 \\
\hline 20 & 9 & 18 & 144 & 50 & 62.609 & 62.674 & -0.065 & -0.104 & 0.104 & 0.033 \\
\hline 21 & 9 & 20 & 144 & 50 & 57.391 & 56.958 & 0.433 & 0.760 & 0.760 & 0.217 \\
\hline 22 & 9 & 10 & 4 & 50 & 38.261 & 38.589 & -0.328 & -0.850 & 0.850 & 0.164 \\
\hline 23 & 9 & 10 & 8 & 50 & 43.478 & 43.056 & 0.423 & 0.982 & 0.982 & 0.211 \\
\hline 24 & 9 & 10 & 12 & 50 & 46.957 & 46.723 & 0.234 & 0.500 & 0.500 & 0.117 \\
\hline 25 & 9 & 10 & 24 & 50 & 53.913 & 53.966 & -0.053 & -0.098 & 0.098 & 0.026 \\
\hline 26 & 9 & 10 & 48 & 50 & 60.870 & 60.936 & -0.067 & -0.109 & 0.109 & 0.033 \\
\hline 27 & 9 & 10 & 72 & 50 & 66.087 & 66.041 & 0.046 & 0.069 & 0.069 & 0.023 \\
\hline 28 & 9 & 10 & 96 & 50 & 71.304 & 71.395 & -0.090 & -0.127 & 0.127 & 0.045 \\
\hline 29 & 9 & 10 & 120 & 50 & 76.522 & 76.370 & 0.151 & 0.198 & 0.198 & 0.076 \\
\hline 30 & 9 & 10 & 144 & 50 & 80.000 & 79.752 & 0.248 & 0.311 & 0.311 & 0.124 \\
\hline 31 & 9 & 10 & 168 & 50 & 81.739 & 81.359 & 0.380 & 0.467 & 0.467 & 0.190 \\
\hline 32 & 9 & 10 & 192 & 50 & 81.739 & 81.823 & -0.084 & -0.102 & 0.102 & 0.042 \\
\hline 33 & 9 & 10 & 216 & 50 & 81.739 & 81.789 & -0.050 & -0.061 & 0.061 & 0.025 \\
\hline 34 & 9 & 10 & 240 & 50 & 81.739 & 81.642 & 0.098 & 0.120 & 0.120 & 0.049 \\
\hline 35 & 9 & 10 & 264 & 50 & 81.739 & 81.547 & 0.192 & 0.236 & 0.236 & 0.096 \\
\hline 36 & 9 & 10 & 288 & 50 & 81.739 & 81.552 & 0.187 & 0.229 & 0.229 & 0.093 \\
\hline 37 & 9 & 10 & 312 & 50 & 81.739 & 81.652 & 0.087 & 0.107 & 0.107 & 0.044 \\
\hline 38 & 9 & 10 & 336 & 50 & 81.739 & 81.823 & -0.084 & -0.102 & 0.102 & 0.042 \\
\hline 39 & 9 & 10 & 360 & 50 & 81.739 & 82.041 & -0.302 & -0.369 & 0.369 & 0.151 \\
\hline 40 & 9 & 10 & 144 & 50 & 81.739 & 81.359 & 0.380 & 0.467 & 0.467 & 0.190 \\
\hline 41 & 9 & 10 & 144 & 100 & 78.478 & 80.183 & -1.704 & -2.126 & 2.126 & 0.852 \\
\hline 42 & 9 & 10 & 144 & 200 & 76.957 & 77.737 & -0.781 & -1.004 & 1.004 & 0.390 \\
\hline 43 & 9 & 10 & 144 & 500 & 73.783 & 73.903 & -0.120 & -0.162 & 0.162 & 0.060 \\
\hline 44 & 9 & 10 & 144 & 800 & 70.978 & 70.862 & 0.116 & 0.164 & 0.164 & 0.058 \\
\hline 45 & 9 & 10 & 144 & 1000 & 67.435 & 67.201 & 0.233 & 0.347 & 0.347 & 0.117 \\
\hline 46 & 9 & 10 & 144 & 1200 & 64.348 & 64.395 & -0.048 & -0.074 & 0.074 & 0.024 \\
\hline 47 & 9 & 10 & 144 & 1500 & 61.174 & 61.195 & -0.021 & -0.034 & 0.034 & 0.010 \\
\hline 48 & 9 & 10 & 144 & 1800 & 58.152 & 57.900 & 0.252 & 0.436 & 0.436 & 0.126 \\
\hline 49 & 9 & 10 & 144 & 2000 & 55.250 & 55.696 & -0.446 & -0.801 & 0.801 & 0.223 \\
\hline
\end{tabular}


Table 7 Comparison of experimental and predicted As(V) removal efficiency on all data (Training, validation and testing)

\begin{tabular}{|c|c|c|c|c|c|c|c|c|c|c|}
\hline $\begin{array}{l}\text { Run } \\
\text { No. }\end{array}$ & $\mathrm{pH}$ & $\begin{array}{l}\text { Inoculum } \\
\text { size }\end{array}$ & $\begin{array}{l}\text { Contact } \\
\text { time }(h)\end{array}$ & $\begin{array}{l}\text { Initial arsenic } \\
\text { conc. }(\mathrm{mg} / \mathrm{L})\end{array}$ & $\begin{array}{l}\text { Actual } \\
\text { Removal (\%) }\end{array}$ & $\begin{array}{l}\text { Predicted } \\
\text { Removal }(\%)\end{array}$ & $\begin{array}{l}\text { Residual } \\
(\%)\end{array}$ & $\begin{array}{l}\text { Error } \\
(\%)\end{array}$ & $\begin{array}{l}\text { Absolute } \\
\text { error }\end{array}$ & $\begin{array}{l}\text { Standard } \\
\text { deviation (SD) }\end{array}$ \\
\hline 1 & 2 & 10 & 144 & 50 & 8.154 & 8.092 & 0.062 & 0.768 & 0.768 & 0.031 \\
\hline 2 & 3 & 10 & 144 & 50 & 17.385 & 16.093 & 1.292 & 8.026 & 8.026 & 0.646 \\
\hline 3 & 4 & 10 & 144 & 50 & 29.692 & 29.643 & 0.050 & 0.168 & 0.168 & 0.025 \\
\hline 4 & 5 & 10 & 144 & 50 & 40.462 & 40.405 & 0.057 & 0.141 & 0.141 & 0.028 \\
\hline 5 & 6 & 10 & 144 & 50 & 58.923 & 55.644 & 3.279 & 5.893 & 5.893 & 1.640 \\
\hline 6 & 7 & 10 & 144 & 50 & 68.154 & 66.615 & 1.539 & 2.310 & 2.310 & 0.769 \\
\hline 7 & 8 & 10 & 144 & 50 & 78.923 & 77.453 & 1.470 & 1.898 & 1.898 & 0.735 \\
\hline 8 & 9 & 10 & 144 & 50 & 83.538 & 83.284 & 0.255 & 0.306 & 0.306 & 0.127 \\
\hline 9 & 10 & 10 & 144 & 50 & 69.692 & 69.918 & -0.225 & -0.322 & 0.322 & 0.113 \\
\hline 10 & 11 & 10 & 144 & 50 & 37.385 & 38.826 & -1.441 & -3.711 & 3.711 & 0.720 \\
\hline 11 & 12 & 10 & 144 & 50 & 17.385 & 15.227 & 2.157 & 14.166 & 14.166 & 1.079 \\
\hline 12 & 9 & 2 & 144 & 50 & 66.615 & 68.093 & -1.478 & -2.170 & 2.170 & 0.739 \\
\hline 13 & 9 & 4 & 144 & 50 & 71.231 & 71.284 & -0.053 & -0.075 & 0.075 & 0.027 \\
\hline 14 & 9 & 6 & 144 & 50 & 75.846 & 75.825 & 0.021 & 0.027 & 0.027 & 0.010 \\
\hline 15 & 9 & 8 & 144 & 50 & 80.462 & 80.446 & 0.016 & 0.020 & 0.020 & 0.008 \\
\hline 16 & 9 & 10 & 144 & 50 & 83.538 & 83.284 & 0.255 & 0.306 & 0.306 & 0.127 \\
\hline 17 & 9 & 12 & 144 & 50 & 80.462 & 80.666 & -0.205 & -0.254 & 0.254 & 0.102 \\
\hline 18 & 9 & 14 & 144 & 50 & 75.846 & 75.764 & 0.082 & 0.109 & 0.109 & 0.041 \\
\hline 19 & 9 & 16 & 144 & 50 & 71.231 & 71.058 & 0.173 & 0.243 & 0.243 & 0.086 \\
\hline 20 & 9 & 18 & 144 & 50 & 68.154 & 66.965 & 1.189 & 1.775 & 1.775 & 0.594 \\
\hline 21 & 9 & 20 & 144 & 50 & 65.077 & 63.177 & 1.900 & 3.007 & 3.007 & 0.950 \\
\hline 22 & 9 & 10 & 4 & 50 & 40.462 & 41.745 & -1.284 & -3.075 & 3.075 & 0.642 \\
\hline 23 & 9 & 10 & 8 & 50 & 46.615 & 44.578 & 2.037 & 4.570 & 4.570 & 1.019 \\
\hline 24 & 9 & 10 & 12 & 50 & 51.231 & 47.238 & 3.992 & 8.451 & 8.451 & 1.996 \\
\hline 25 & 9 & 10 & 24 & 50 & 57.385 & 54.229 & 3.155 & 5.818 & 5.818 & 1.578 \\
\hline 26 & 9 & 10 & 48 & 50 & 68.154 & 64.334 & 3.819 & 5.937 & 5.937 & 1.910 \\
\hline 27 & 9 & 10 & 72 & 50 & 74.308 & 70.883 & 3.425 & 4.832 & 4.832 & 1.713 \\
\hline 28 & 9 & 10 & 96 & 50 & 78.923 & 76.095 & 2.828 & 3.716 & 3.716 & 1.414 \\
\hline 29 & 9 & 10 & 120 & 50 & 82.000 & 80.525 & 1.475 & 1.832 & 1.832 & 0.737 \\
\hline 30 & 9 & 10 & 144 & 50 & 83.538 & 83.284 & 0.255 & 0.306 & 0.306 & 0.127 \\
\hline 31 & 9 & 10 & 168 & 50 & 85.077 & 84.567 & 0.510 & 0.603 & 0.603 & 0.255 \\
\hline 32 & 9 & 10 & 192 & 50 & 85.077 & 85.076 & 0.001 & 0.001 & 0.001 & 0.001 \\
\hline 33 & 9 & 10 & 216 & 50 & 85.077 & 85.241 & -0.164 & -0.192 & 0.192 & 0.082 \\
\hline 34 & 9 & 10 & 240 & 50 & 85.077 & 85.256 & -0.179 & -0.210 & 0.210 & 0.090 \\
\hline 35 & 9 & 10 & 264 & 50 & 85.077 & 85.207 & -0.130 & -0.153 & 0.153 & 0.065 \\
\hline 36 & 9 & 10 & 288 & 50 & 85.077 & 85.135 & -0.058 & -0.068 & 0.068 & 0.029 \\
\hline 37 & 9 & 10 & 312 & 50 & 85.077 & 85.062 & 0.015 & 0.017 & 0.017 & 0.007 \\
\hline 38 & 9 & 10 & 336 & 50 & 85.077 & 85.009 & 0.068 & 0.080 & 0.080 & 0.034 \\
\hline 39 & 9 & 10 & 360 & 50 & 85.077 & 84.993 & 0.084 & 0.098 & 0.098 & 0.042 \\
\hline 40 & 9 & 10 & 144 & 50 & 85.077 & 84.567 & 0.510 & 0.603 & 0.603 & 0.255 \\
\hline 41 & 9 & 10 & 144 & 100 & 83.038 & 84.179 & -1.141 & -1.355 & 1.355 & 0.570 \\
\hline 42 & 9 & 10 & 144 & 200 & 81.000 & 81.860 & -0.860 & -1.051 & 1.051 & 0.430 \\
\hline 43 & 9 & 10 & 144 & 500 & 77.362 & 77.685 & -0.323 & -0.416 & 0.416 & 0.162 \\
\hline 44 & 9 & 10 & 144 & 800 & 76.519 & 76.330 & 0.190 & 0.248 & 0.248 & 0.095 \\
\hline 45 & 9 & 10 & 144 & 1000 & 72.700 & 72.917 & -0.217 & -0.297 & 0.297 & 0.108 \\
\hline 46 & 9 & 10 & 144 & 1200 & 69.385 & 69.357 & 0.027 & 0.039 & 0.039 & 0.014 \\
\hline 47 & 9 & 10 & 144 & 1500 & 66.044 & 66.053 & -0.009 & -0.014 & 0.014 & 0.004 \\
\hline 48 & 9 & 10 & 144 & 1800 & 62.442 & 62.378 & 0.064 & 0.103 & 0.103 & 0.032 \\
\hline 49 & 9 & 10 & 144 & 2000 & 59.883 & 60.015 & -0.132 & -0.221 & 0.221 & 0.066 \\
\hline
\end{tabular}



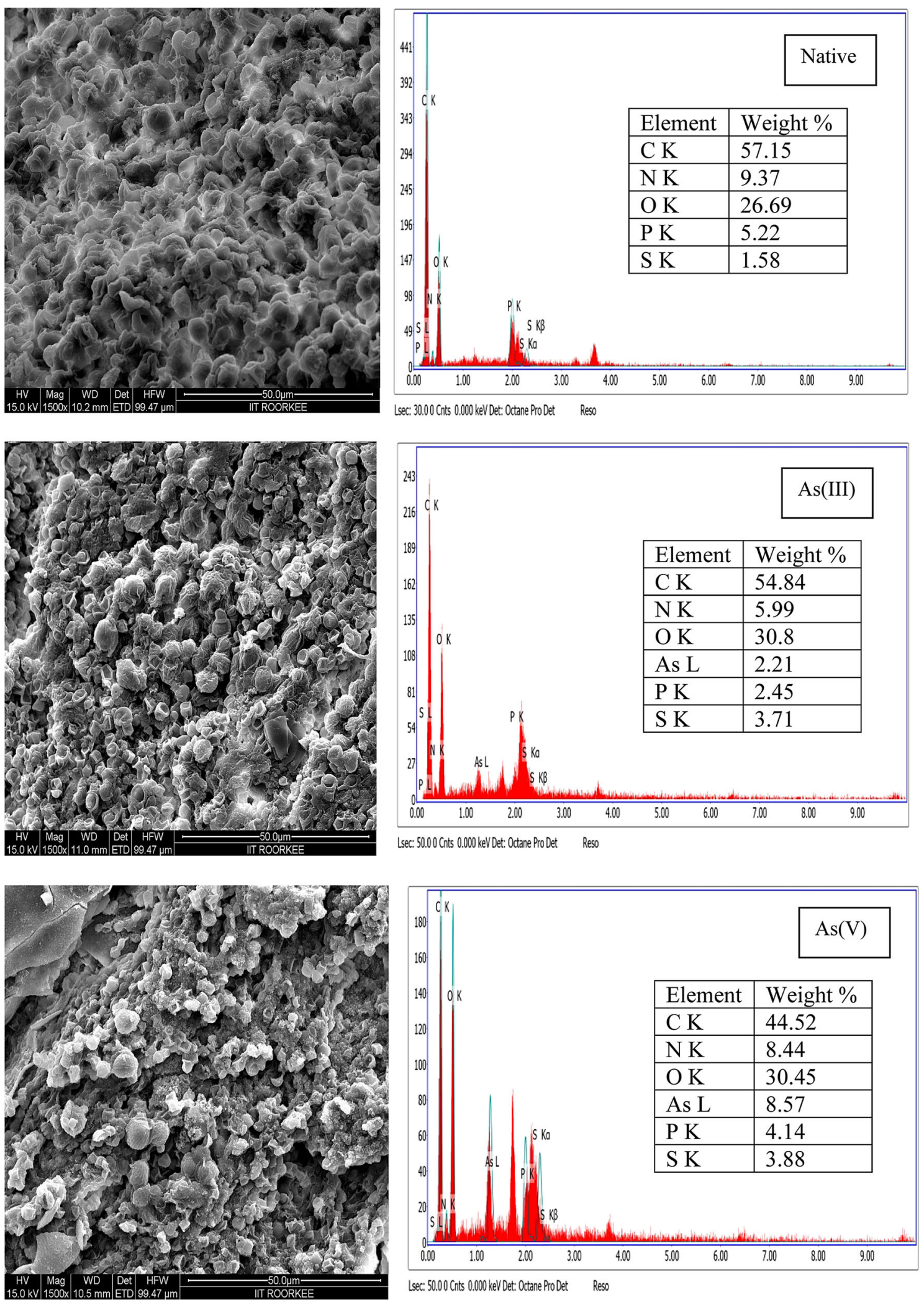

Leec: 50.00 Cits 0.000 keV Det: Octane Pro Det Reso

Fig. 14 Scanning electron micrographs (SEM) $(1500 \times)$ and EDX of native Chlorella pyrenoidosa, As(III) loaded biomass and As(V) loaded biomass 
the model can be utilized for purpose of prediction with sensible exactness. The progress of the suggested ANN model is an effort in the direction of an increasing concern to apply ANN modelling method to the field of biosorption of contaminants from water bodies (Texier et al. 2002; Aber et al. 2009). Conversely the current investigation is focused on modelling of phycoremediation of arsenic [either $\mathrm{As}(\mathrm{III})$ or $\mathrm{As}(\mathrm{V})]$ using a new algae $C$. pyrenoidosa. These studies determine that ANN approach is reasonably effective in modelling complex biological phenomenon.

Comparison of experimental and predicted removal efficiency on all data (Training, validation and testing) is presented in Tables 6 and 7 for As(III) and As(V), respectively. Consistent with normal probability density function of error \% values, it can be expected that the errors are distributed normally and the ANN model can be utilized for the purpose of prediction with realistic accurateness.

The statistical analysis of simulated output of 4:5:1 three-layer network topology with the experimental output values are listed in 7 and 8 for $\operatorname{As}(\mathrm{III})$ and $\mathrm{As}(\mathrm{V})$, respectively. The SD less than 1.0 shows good agreement between experimental and predicted results. Then the higher value $(>1)$ of SD may be because of the insufficient data to train the network.

\section{Characterization of microalgae}

Figure 14 shows the scanning electron microscopy (SEM) images of native microalgal biomass and As(III) and As $(\mathrm{V})$ loaded microalgal biomass, respectively. In both images, two types of structure have been seen. The spherical shape represents C. pyrenoidosa. From Fig. 14, it is found that in native microalgal biomass the surface is smooth while after arsenic (either As(III) or As(V)) treatment the surface becomes rough in both the microalgal structures. Such roughness of the surface may be because of the phycoremediation of arsenic [either As(III) or As $(V)$ ] over the surface that makes the surface coarser than its original form. The nodules are not clearly visible in the SEM. The cells seem to be glued to each other. It was because of more EPS production, which is one of the wellknown responses against stress. It has also been seen that there has been very little or no change in the fraction of spherical shape of $C$. pyrenoidosa before and after arsenic (either $\mathrm{As}(\mathrm{III})$ or $\mathrm{As}(\mathrm{V}))$ removal. It recommends that the presence of arsenic [either $\mathrm{As}(\mathrm{III})$ or $\mathrm{As}(\mathrm{V})]$ does not make the medium selective toward any of the strains and the biological nature of the consortium remains fairly constant. Densities of the nodules also seem to be unaffected by the presence of arsenic [either $\mathrm{As}(\mathrm{III})$ or $\mathrm{As}(\mathrm{V})$ ] signifying that the growth kinetics of the consortium remains unaffected in the presence of arsenic [either As(III) or As(V)] in simulated wastewater.
The corresponding EDX spectra of the unloaded and loaded microalgae was collected and given in Fig. 14. The presence of arsenic on the loaded microalgae surface was exposed evidently. This outcome again established the occurrence of phycoremediation of arsenic by the microalgae.

\section{Conclusion}

The present work reveals effective removal of As (III) and $\mathrm{As}(\mathrm{V})$ ions from the $50 \mathrm{mg} / \mathrm{L}$ synthetic wastewater utilizing $C$. pyrenoidosa biomass with maximum removal efficiency of 81.73913 and $85.07692 \%$, respectively. A threelayer feed-forward back propagation of neural network with Levenberg-Marquardt training algorithm is successfully accepted for predicting the response of the phycoremediation process for both $\mathrm{As}(\mathrm{III})$ and $\mathrm{As}(\mathrm{V})$. The model with architecture of 4:5:1 presents good agreements with the actual experimental and predicted values of both $\mathrm{As}(\mathrm{III})$ and $\mathrm{As}(\mathrm{V})$. A comparison between the experimental data and ANN model results gave a high correlation coefficient ( $R_{\text {all_ANN }}^{2}$ equal to 0.99987 for both As(III) and $\operatorname{As}(\mathrm{V}))$, showed that the model is capable for predicting the phycoremediation of both As(III) and $\mathrm{As}(\mathrm{V})$ from wastewater. The model can be again extended comprising more number of variables and experimental data for exploiting basic principle of $\mathrm{As}(\mathrm{III})$ and $\mathrm{As}(\mathrm{V})$ removal from wastewater utilizing algal biomass. Neural models with rapid convergence ability may be tested with experimental results for reducing the computational efforts. For concluding, a simulation on the basis of the ANN model can deliver a further contribution for developing a better understanding of the dynamic behaviour of process where still some phenomena cannot be clarified in all detail.

Acknowledgements Our thanks to Indian Institute of Technology, Roorkee for providing necessary facilities and to Ministry of Human Resource Development, Government of India for financial support. The thoughtful comments by Dr. Enrico Drioli, the Editor-in-Chief and one anonymous reviewer are highly appreciated.

Open Access This article is distributed under the terms of the Creative Commons Attribution 4.0 International License (http://creativecommons. org/licenses/by/4.0/), which permits unrestricted use, distribution, and reproduction in any medium, provided you give appropriate credit to the original author(s) and the source, provide a link to the Creative Commons license, and indicate if changes were made.

\section{References}

Aber S, Amani-Ghadim AR, Mirzajani V (2009) Removal of Cr(VI) from polluted solutions by electrocoagulation: modeling of 
experimental results using artificial neural network. J Hazard Mater 171:484-490

Aghav RM (2011) Sunil Kumar, S.N. Mukherjee, Artificial neural network modeling in competitive adsorption of phenol and resorcinol from water environment using some carbonaceous adsorbents. J Hazard Mater 188:67-77

APHA, AWWA, WEF (1998) Standard methods for examination of water and wastewater, 20th edn. New York

Arunakumara KKIU, Zhang X (2008) Heavy metal bioaccumulation and toxicity with special reference to microalgae. Journal of Ocean University of China 7(1):60-64

Aryal M, Ziagova M, Liakopoulou-Kyriakides M (2010) Study on arsenic biosorption using Fe(III)-treated biomass of Staphylococcus Xylosus. Chem Eng J 162:178-185

Baptista MS, Vasconcelos MT (2006) Cyanobacteria metal interactions: requirements, toxicity, and ecological implications. Crit Rev Microbiol 32:127-137

Basha CA, Bhadrinarayana NS, Anantharaman N, Begum KMMS (2008) Heavy metal removal from copper smelting effluent using electrochemical cylindrical flow reactor. J Hazard Mater 152:71-78

Basha S, Murthy ZVP, Jha B (2009) Sorption of $\mathrm{Hg}$ (II) onto Carica Papaya: experimental studies and design of batch sorber. Chem Eng J 147:226-234

Bingöl D, Hercan M, Elevli S, Kilıc E (2012) Comparison of the results of response surface methodology and artificial neural network for the biosorption of lead using black cumin. Bioresource Technol 112:111-115

Boddu VM, Abburi K, Talbott JL, Smith ED, Haasch R (2008) Removal of arsenic (III) and arsenic (V) from aqueous medium using chitosan-coated biosorbent. Water Res 42:633-642

Brinza L, Dring MJ, Gavrilescu M (2007) Marine micro- and macroalgal species as biosorbent for heavy metals. Environ Eng Manag J 6:237-251

Chairez I, Garcia-Peña I, Cabrera A (2009) Dynamic numerical reconstruction of a fungal biofiltration system using differential neural network. J Process Contr 19:1103-1110

Chakraborty N, Banerjee A, Pal R (2011) Biomonitoring of lead, cadmium and chromium in environmental water from Kolkata, North and South-24 Parganas using algae as bioreagent. J Algal Biomass Utln 2:27-41

Cho DY, Lee S, Park S, Chung A (1994) Studies on biosorption of heavy metals onto Chlorella vulgaris. J Environ Sci Health A 29:389-409

Chojnacka K, Chojnacki A, Górecka H (2005) Biosorption of $\mathrm{Cr}^{3+}$, $\mathrm{Cd}^{2+}$ and $\mathrm{Cu}^{2+}$ ions by blue-green algae Spirulina sp.: kinetics, equilibrium and the mechanism of the process. Chemosphere 59(1):75-84

Comte S, Guibaud G, Baudu M (2008) Biosorption properties of extracellular polymeric substances (EPS) towards $\mathrm{Cd}, \mathrm{Cu}$ and $\mathrm{Pb}$ for different $\mathrm{pH}$ values. J Hazard Mater 151:185-193

Das BK, Roy A, Koschorreck M, Mandal SM, Wendt-Potthoff K, Bhattacharya J (2009) Occurrence and role of algae and fungi in acid mine drainage environment with special reference to metals and sulfate immobilization. Water Res 43:883-894

Dash RR, Balomajumder C, Kumar A (2009) Removal of cyanide from water and wastewater using granular activated carbon. Chem Eng J 146:408-413

De La Noüe J, Laliberte G, Proulx D (1992) Algae and wastewater. J Appl Phycol 4:247-254

De Philippis R, Colica G, Micheletti E (2011) Exopolysaccharideproducing cyanobacteria in heavy metal removal from water: molecular basis and practical applicability of the biosorption process. Appl Microbiol Biotechnol 92:697-708

Doshi H, Ray A, Kothari IL (2007) Biosorption of cadmium by live and dead Spirulina: iR spectroscopic, kinetics and SEM studies. Curr Microbiol 54:213-218
Ekici BB, Aksoy UT (2010) Prediction of building energy consumption by using artificial neural networks. Adv Eng Softw 41:141-147

Elias A, Ibarra-Berastegi G, Arias R, Barona A (2006) Neural networks as a tool for control and management of a biological reactor for treating hydrogen sulphide. Bioproc Biosyst Eng 29:129-136

European commission Directive (1998) 98/83/EC, related with drinking water quality intended for human consumption. Belgium, Brussels

Franchino M, Comino E, Bona F, Riggio VA (2013) Growth of three microalgae strains and nutrient removal from an agro-zootechnical digestate. Chemosphere 92:738-744

Giri AK, Patel RK, Mahapatra SS (2011) Artificial neural network (ANN) approach for modelling of arsenic (III) biosorption from aqueous solution by living cells of Bacillus cereus biomass. Chem Eng J 178:15-25

Giri AK, Patel RK, Mahapatra SS, Mishra PC (2013) Biosorption of arsenic (III) from aqueous solution by living cells of Bacillus cereus. Environ Sci Pollut Res 20:1281-1291

Gorashi F, Abdullah A (2012) Prediction of water quality index using back propagation network algorithm case study: Gombak river. J Eng Sci Technol 7:447-461

Gupta VK, Rastogi A, Saini VK, Jain N (2006) Biosorption of copper (II) from aqueous solutions by Spirogyra species. J Colloid Interface Sci 296:59-63

Hagan MT, Demuth HB, Beale MH (1996) Neural Network Design. PWS Publishing Company, Boston

Hansen HK, Ribeiro A, Mateus E (2006) Biosorption of arsenic (V) with Lessonia nigrescens. Miner Eng 19:486-490

Hu S, Lau KWK, Wu M (2001) Cadmium sequestration in Chlamydomonas reinhardtii. Pl Sci 161:987-996

$\mathrm{Hu}$ J, Lo IMC, Chen G (2005) Fast removal and recovery of $\mathrm{Cr}(\mathrm{VI})$ using surface-modified jacobsite $\left(\mathrm{MnFe}_{2} \mathrm{O}_{4}\right)$ nanoparticles. Langmuir 21:11173-11179

Jaafarzadeh N, Ahmadi M, Amiri H, Yassin MH, Martinez SS (2012) Predicting Fenton modification of solid waste vegetable oil industry for arsenic removal using artificial neural networks. J Taiwan Inst Chem Eng 43:873-878

Jayanthi M, Kanchana D, Saranraj P, Sujitha D (2013) Bioremediation of Toxic Heavy Metal Chromium in Tannery Effluent Using Bacteria. Appl. J. Hygiene 2:8-14

John J (2000) A self-sustainable remediation system for acidic mine voids. In: 4th International conference of diffuse pollution 506-511

Kumar KS, Ganesan K, Rao PVS (2007) Phycoremediation of heavy metals by the three-color forms of Kappaphycus alvarezii. J Hazard Mater 143:590-592

Kumar TSJ, Balavigneswaran CK, Srinivasakumar KP (2013) Biodiesel fuel production from marine microalgae Isochrysis galbana, Pavlova lutheri, Dunaliella alina and measurement of its viscosity and density. Int J Marine Sci 3:33-35

Kumar KS, Dahms H-U, Won E-J, Lee J-S, Shin K-H (2015) Microalgae: a promising tool for heavy metal remediation. Ecotoxicol Environ Saf 113:329-352

Kumari P, Sharma P, Srivastava S, Srivastava MM (2006) Biosorption studies on shelled Moringa oleifera Lamarck seed powder: removal and recovery of arsenic from aqueous system. Int $\mathbf{J}$ Miner Process 78:131-139

Kundu S, Gupta AK (2006) Arsenic adsorption onto iron oxide-coated cement (IOCC): regression analysis of equilibrium data with several isotherm models and their optimization. Chem Eng $\mathbf{J}$ 122:93-106

Levenberg K (1944) A method for the solution of certain problems in least squares. Quart Appl Math 5:164-168 
Mandal BK, Suzuki KT (2002) Arsenic round the world: a review. Talanta 58:201-235

Mandal S, Padhi T, Patel RK (2011) Studies on the removal of arsenic (III) from water by a novel hybrid material. J Hazard Mater 192:899-908

Mandal S, Mahapatra SS, Sahu MK, Patel RK (2015) Artificial neural network modelling of As(III) removal from water by novel hybrid material. Process Safe Environ Protect 93:249-264

Marquardt D (1963) An algorithm for least-squares estimation of nonlinear parameters. SIAM J Appl Math 11:431-441

Mashitah MD, Zulfadhly Z, Bhatia S (1999) Binding mechanism of heavy metals biosorption by Pycnoporus sanguineus. J Artif Cells Blood Substit Immobil Biotechnol 27:441-445

Mishra V, Majumder CB, Agarwal VK (2010) Zn(II) ion biosorption onto surface of eucalyptus leaf biomass: isotherm, kinetic, and mechanistic modeling. Clean Soil Air Water 38:1062-1073

Mohan D, Pittman CU Jr (2007) Arsenic removal from water/ wastewater using adsorbents: a critical review. J Hazard Mater 142:1-53

Mondal P, Majumder CB, Mohanty B (2006) Laboratory based approaches for arsenic remediation from contaminated water: recent developments. J Hazard Mater 137:464-479

Mondal P, Balomajumder C, Mohanty B (2007) A laboratory study for the treatment of arsenic, iron, and manganese bearing ground water using $\mathrm{Fe}^{3+}$ impregnated activated carbon: effects of shaking time, $\mathrm{pH}$ and temperature. J Hazard Mater 144:420-426

Monteiro CM, Castro PML, Malcata FX (2012) Metal uptake by microalgae: underlying mechanisms and practical applications. Biotechnol Prog 28(2):299-311

Morrison GMP, Bately GE, Florence TM (1989) Metal speciation and toxicity. Chem $\mathrm{Br}$ 25:791-796

Movagharnejad K, Nikzad M (2007) Modeling of tomato drying using artificial neural network. Comput Electron Agric 59:78-85

Muthukumaran M, Raghavan BG, Subramanian VV, Sivasubramanian V (2005) Bioremediation of industrial effluent using micro algae. Indian Hydrobiology 7:105-122

Olguín EJ (2003) Phycoremediation: key issues for cost-effective nutrient removal processes. Biotechnol Adv 22:81-91

Oswald WJ, Gottas HB (1957) Photosynthesis in sewage treatment. Trans Am Soc Civ Eng 122:73-105

Park KC, Whitney C, Mc Nichol J, Dickinson KE, MacQuarrie S, Skrupski BP, Zhou J, Wilson K, O'Leary SJB, McGinn PJ (2011) Mixotrophic and photoautotrophic cultivation of 14 microalgae isolates from Saskatchewan, Canada: potential applications for wastewater remediation for biofuel production. J Appl Phycol 24:339-348

Pawlik-Skowrónska B, Pirszel J, Kalinowska R (2004) T. Skowrónski, Arsenic availability, toxicity and direct role of GSH and phytochelatins in As detoxification in the green alga Stichococcus bacillaris. Aquat Toxicol 70:201-212

Pillewan P, Mukherjee S, Roychowdhury T, Das S, Bansiwal A, Rayalu S (2011) Removal of As(III) and As(V) from water by copper oxide incorporated mesoporous alumina. J Hazard Mater 186:367-375

Pinto E, Sigaud-Kutner TCS, Leitao MAS, Okamoto OK, Morse D, Colepicolo P (2003) Heavy metal-induced oxidative stress in algae. J Phycol 39:1008-1018

Prasad KS, Ramanathan AL, Paul J, Subramanian V, Prasad R (2013) Biosorption of arsenite $\left(\mathrm{As}^{+3}\right)$ and arsenate $\left(\mathrm{As}^{+5}\right)$ from aqueous solution by Arthrobacter sp. Biomass, Environmental Technology 34(19):2701-2708

Priyadarshani I, Sahu D, Rath B (2011) Microalgae bioremediation: current practices and perspectives. J Biochem Tech 3:299-304

Radjenovic J, Petrovic M, Barcelo D (2009) Fate and distribution of pharmaceuticals in wastewater and sewage sludge of the conventional activated sludge (CAS) and advanced membrane bioreactor (MBR) treatment. Water Res 43:831-841

Ranjan D, Talat M, Hasan SH (2009) Biosorption of arsenic from aqueous solution using agricultural residue 'rice polish'. J Hazard Mater 166:1050-1059

Rao PH, Kumar RR, Raghavan BG, Subramanian VV, Sivasubramanian V (2011) Application of phycoremediation technology in the treatment of wastewater from a leather-processing chemical manufacturing facility, Water S.A. 37:7-14

Raungsomboon S, Chidthaisong A, Bunnag B, Inthorn D, Harveya NW (2008) Removal of lead $\left(\mathrm{Pb}^{2+}\right)$ by the cyanobacterium Gloeocapsa sp. Bioresour Technol 99:5650-5658

Razmovzki R, Sciban M (2008) Biosorption of Cr(VI) and Cu(II) by waste tea fungal biomass. Ecol Eng 34:179-186

Ren Y, Li N, Feng J, Luan T, Wen Q, Li Z, Zhang M (2012) Adsorption of $\mathrm{Pb}$ (II) and $\mathrm{Cu}(\mathrm{II})$ from aqueous solution on magnetic porous ferrospinel $\mathrm{MnFe}_{2} \mathrm{O}_{4}$. J Colloid Interface Sci 367:415-421

Rene ER, Veiga MC, Kennes C (2009) Experimental and neural model analysis of styrene removal from polluted air in a biofilter. J Chem Technol Biot 84:941-948

Renuka N, Sood A, Prasanna R, Ahluwalia AS (2015) Phycoremediation of wastewaters: a synergistic approach using microalgae for bioremediation and biomass generation Int. J Environ Sci Technol 12:1443-1460

Richards RG, Mullins BJ (2013) Using microalgae for combined lipid production and heavy metal removal from leachate. Ecol Model 249:59-67

Sadowski Z (2001) Effect of biosorption of $\mathrm{Pb}(\mathrm{II}), \mathrm{Cu}(\mathrm{II})$ and $\mathrm{Cd}(\mathrm{II})$ on the zeta potential and flocculation of Nocardia sp. Miner Eng 14:547-552

Sahu AK, Siljudalen J, Trydal T, Rusten B (2013) Utilization of wastewater nutrients for microalgae growth for anaerobic digestion. J Environ Manag 122:113-120

Singh TS, Pant KK (2006) Kinetics and mass transfer studies on the adsorption of arsenic onto activated alumina and iron oxide impregnated activated alumina. Water Qual Res J Can 41:147-156

Smedley PL, Nicolli HB, Macdonald DMJ, Barros AJ, Tullio JO (2002) Hydrogeochemistry of arsenic and other inorganic constituents in groundwaters from La Pampa, Argentina. Appl Geochem 17:259-284

Soeprobowati TR, Hariyati R (2013) Bioaccumulation of $\mathrm{Pb}, \mathrm{Cd}, \mathrm{Cu}$, and $\mathrm{Cr}$ by Porphyridium cruentum (S.F. Gray) Nägeli, International. J Marine Sci 3:212-218

Srinath T, Verma T, Ramteke PW, Garg SK (2002) Chromium (VI) biosorption and bioaccumulation by chromate resistant bacteria. Chemospere 48(2002):427-435

Stillman MJ (1995) Metallothioneins. Coord Chem Rev 144:461-511

Su Y, Mennerich A, Urbana B (2012) Synergistic cooperation between wastewater-born algae and activated sludge for wastewater treatment: influence of algae and sludge inoculation ratios. Bioresour Technol 105:67-73

Terry PA, Stone W (2002) Biosorption of cadmium and copper contaminated water by Scenedesmus abundans. Chemosphere 47:249-255

Texier AC, Andres Y, Faur-Brasquet C, Cloirec LP (2002) Fixed-bed study for lanthanide ( $\mathrm{La}, \mathrm{Eu}, \mathrm{Yb}$ ) ions removal from aqueous solutions by immobilized pseudomonas aeruginosa: experimental data and modelization. Chemosphere 47:333-342

Turan NG, Mesci B, Ozgonenel O (2011a) Artificial neural network (ANN) approach for modeling Zn (II) adsorption from leachate using a new biosorbent. Chem Eng J 173:98-105

Turan NG, Mesci B, Ozgonenel O (2011b) The use of artificial neural networks (ANN) for modeling of adsorption of $\mathrm{Cu}$ (II) from industrial leachate by pumice. Chem Eng J 171:1091-1097 
US EPA (2000) Arsenic occurrence in public drinking water supplies, Washington, DC

Velásquez L, Dussan J (2009) Biosorption and bioaccumulation of heavy metals on dead and living biomass of Bacillus sphaericus. J Hazard Mater 167:713-716

Volesky B (2007) Biosorption and me. Water Res 41:4017-4029

Volesky B, Holan ZR (1995) Biosorption of heavy metals. Biotechnol Prog 11:235-250
WHO (1993) Guidelines for drinking water quality, World Health Organization, Geneva, p. 41

Yadavalli R, Heggers GRVN (2013) Two stage treatment of dairy effluent using immobilized Chlorella pyrenoidosa. J. Environ. Health Sci. Eng. 11:1-6

Zhang G, Qu R, Sun C, Ji C, Chen H, Wang C, Niu Y (2008) Adsorption for metal ions of chitosan coated cotton fiber. J Appl Polym Sci 110:2321-2327 